\title{
Meta-analysis and review: effectiveness, safety, and central port design of the intraocular collamer lens
}

This article was published in the following Dove Press journal:

Clinical Ophthalmology

9 June 2016

Number of times this article has been viewed

\section{Mark Packer}

Mark Packer MD Consulting, Inc., Boulder, CO, USA
Correspondence: Mark Packer Mark Packer MD Consulting, Inc., I400 Bluebell Avenue, Boulder, CO 80302, USA

Tel + I 54 | 9|5 029|

Email mark@markpackerconsulting.com
Abstract: The purpose of this review is to summarize relevant data from publications appearing in the peer-reviewed scientific literature over the past decade since US Food and Drug Administration approval of the implantable collamer lens (ICL), and, in particular, to review studies relating to sizing methodology, safety, and effectiveness, as well as more recent studies reporting clinical outcomes of the V4c Visian ICL with KS Aquaport, VICMO. A literature search was conducted using two databases, PubMed.gov and Science.gov, to identify all articles published after 2005 related to the Visian ICL (STAAR Surgical, Inc.). Articles were examined for their relevance to sizing methodology, clinical safety, and effectiveness, and the references cited in each article were also searched for additional relevant publications. The literature review revealed that all currently reported methods of determining the best-fit size of the ICL achieve similarly satisfactory results in terms of vault, the safe distance between the crystalline lens and the ICL. Specifically, meta-analysis demonstrated that sulcus-to-sulcus and white-to-white measurement-based sizing methods do not result in clinically meaningful nor statistically significant differences in vault (two-sample two-sided $t$-test using pooled mean and standard deviations; $t(2,594)=1.33 ; P=0.18)$. The reported rates of complications related to vault are very low, except in two case series where additional risk factors such as higher levels of myopia and older age impacted the incidence of cataract. On the basis of preclinical studies and initial clinical reports, with up to 5 years of follow-up, the new VICMO central port design holds promise for further reduction of complications. Given its safety record and the significant improvement in vision and quality of life that the ICL makes possible, the benefits of ICL implantation outweigh the risks.

Keywords: refractive surgery, Phakic lens, posterior chamber, myopia

\section{Introduction}

One decade has passed since the United States Food and Drug Administration (US FDA) determined that implantation of the STAAR Visian Implantable Collamer Lens (ICL, STAAR Surgical, Monrovia, CA, USA) is a safe and effective refractive procedure for the correction of myopia. ${ }^{1}$ Worldwide, the Visian ICL has been marketed for approximately two decades, and over 550,000 lenses have been implanted. ${ }^{2}$ The benefits of the ICL for the correction of moderate-to-high myopia and myopic astigmatism ${ }^{3}$ include predictable, stable refractive correction ${ }^{4}$ and a high efficacy index, ${ }^{5}$ as well as improvement in quality of vision ${ }^{6}$ and quality of life. ${ }^{7}$ Long-term studies have investigated the safety profile of the ICL and demonstrated generally low rates of adverse events. ${ }^{8}$ In a prospective, randomized, study comparing ICL implantation and photorefractive keratectomy, the ICL performed better than photorefractive keratectomy in all measures of safety, efficacy, predictability, and stability, supporting the ICL as a viable alternative to this popular refractive surgical procedure. ${ }^{6}$ 
Nevertheless, controversies remain regarding methodology for selection of the implant size, and the relationship of implant size to safety. ${ }^{9}$ In addition, implantation of the US FDA-approved ICL requires that the surgeon perform preoperative laser iridotomies, which means an additional office visit and possible discomfort for patients. A newer design, currently available outside the United States, the V4c Visian ICL with KS Aquaport, VICMO, incorporates a $0.36 \mathrm{~mm}$ diameter port in the center of the optic. The presence of this port obviates the need for preoperative iridotomies.

The purpose of this review is to summarize relevant data from publications appearing in the peer-reviewed scientific literature over the decade since FDA approval of the ICL; in particular, to review effectiveness and analyze studies relating to sizing methodology and clinical safety of the ICL V4 models, as well as more recent studies of the safety and effectiveness of the V4c Visian ICL with KS Aquaport, VICMO.

\section{Effectiveness: refractive outcomes}

In a recent editorial, McLeod ${ }^{10}$ noted that phakic lenses such as the ICL:

Can provide optically superb correction of relatively high

degrees of ametropia that lie well beyond the recommended

range for keratorefractive procedures, such as laser in situ

keratomileusis and photorefractive keratectomy. ${ }^{10}$

He cited, for example, the report from Igarashi et a ${ }^{11}$ demonstrating excellent long-term refractive results in a population of patients with baseline manifest refractive spherical equivalent (MRSE) $-10.19 \pm 2.86 \mathrm{D}$ : mean $\log \mathrm{MAR}$ uncorrected distance visual acuity $0.02 \pm 0.33$ and $73.2 \%$ of eyes with uncorrected distance acuity of $20 / 20$ or better 8 years after surgery.

Large cohort studies with long-term follow-up have found similar results. In a report of 3-year follow-up of 526 eyes of 294 patients with mean preoperative MRSE of $-10.06 \pm 3.74 \mathrm{D}$ participating in the US FDA clinical trial of the ICL, $59.3 \%$ had $20 / 20$ or better uncorrected visual acuity (UCVA), and $94.7 \%$ had $20 / 40$ or better UCVA if best-corrected visual acuity was 20/20 and they were targeted for emmetropia; $67.5 \%$ of patients were within $0.5 \mathrm{D}$ and $88.2 \%$ were within $1.0 \mathrm{D}$ of predicted refraction. ${ }^{4}$ Lee et al ${ }^{12}$ reported 281 eyes of 145 patients who were followed for at least 5 years (mean $=87 \pm 18.9$ months) and had mean preoperative MRSE of $-8.74 \pm 2.27 \mathrm{D}(-4.00$ to $-15.25 \mathrm{D})$. They noted $60.5 \%$ UCVA $20 / 20$ or better:

At the end of follow up, the postoperative logMAR uncorrected distance visual acuity (UDVA) was 0.30 (approximately 6/12) or better in 254 eyes (90.4\%), 0.10 (approximately 6/7.5) or better in 238 eyes $(84.7 \%$ ) and $0.00(6 / 6)$ or better in 170 eyes $(60.5 \%)$.

Alfonso et a ${ }^{13}$ reported 5-year follow-up of 188 eyes of 111 patients. The authors noted that:

The mean spherical equivalent decreased from $-11.17 \pm$ $3.40 \mathrm{D}$ preoperatively to $-0.23 \pm 0.50 \mathrm{D} 1$ month postoperatively ( $95 \%$ confidence interval $[\mathrm{CI}],-0.15$ to -0.02$)$ and $-0.88 \pm 0.72 \mathrm{D}$ at 5 years $(95 \% \mathrm{CI},-0.68$ to -1.09 ).

Furthermore,

High levels of predictability were achieved early after surgery; 163 eyes (86.7\%) were within $\pm 0.50 \mathrm{D}$ and 182 eyes (96.8\%) were within $\pm 1.00 \mathrm{D}$ of the attempted correction at the 1-month visit. The improvement was maintained over the postoperative follow-up $\left(r^{2}=0.953\right.$ at 5 years $)$.

These results are representative of those reported in the literature as a whole and underscore the efficacy of ICL implantation. As Price and Price ${ }^{3}$ noted in their recent evaluation of the toric ICL for simultaneous treatment of myopia and astigmatism,

Postoperatively, $77 \%$ of treated eyes had uncorrected visual acuity (UCVA) that equaled or exceeded the preoperative best spectacle corrected visual acuity (BSCVA). At 1 year, UCVA was $\geq 20 / 20$ in $83 \%$ of treated eyes and $\geq 20 / 40$ in $96 \% .^{3}$

Refractive outcomes such as these support McLeod's ${ }^{10}$ description of "optically superb correction."

\section{Effectiveness: quality of life and patient satisfaction}

Myopia significantly impacts quality of life. As Rose et $\mathrm{al}^{14}$ pointed out in their investigation of quality of life in myopia,

In many this led to a lack of self confidence because of teasing and feelings of inadequacy; this, in turn, could lead to social isolation and difficulties forming relationships. ${ }^{14}$

Perhaps unsurprisingly, these authors found that the adverse effects of higher degrees of myopia are comparable to a disabling disease such as keratoconus. It stands to reason that correction of myopia is, therefore, likely to engender significant improvement in quality of life.

Improvement in quality of life following ICL implantation has been investigated by Ieong et al, ${ }^{7}$ who reported that "Implantable Collamer lens implantation provided significant gains across a broad range of life activities and is 
clearly a life changing intervention for many patients with high myopia." Kobashi et al ${ }^{15}$ compared quality of life following ICL implantation in patients with mean preoperative MRSE $-9.97 \pm 2.51 \mathrm{D}$ (range, -3.00 to $-14.50 \mathrm{D}$ ) to that following laser-assisted in situ keratomileusis (LASIK) in patients with mean preoperative MRSE $-6.31 \pm 2.20 \mathrm{D}$ (range, -3.00 to $-12.88 \mathrm{D}$ ), and reported, "The scores for activity limitations, symptoms, appearance, and satisfaction with correction were significantly higher in the phakic intraocular lens (pIOL) group than in the LASIK group." They concluded that:

Phakic IOL implantation may offer significant visionrelated quality-of-life advantages (eg, fewer activity limitations and symptoms and better appearance and satisfaction with correction) over wavefront-guided LASIK for myopia in the long term.

Marked improvements in UCVA and substantial gains in quality of life create a strong incentive to consider ICL implantation. These outcomes should be considered in light of safety, to determine whether the expected benefits outweigh the potential risks.

\section{Safety and sizing}

The ICL is intended for surgical implantation within the posterior chamber of the eye, behind the iris and in front of the crystalline lens. Different sizes of overall diameter are manufactured to accommodate normal variations in intraocular anatomy (eg, 12.1, 12.6, 13.2, and $13.7 \mathrm{~mm})$. The relationship of the selected overall diameter of the implanted lens to the dimensions of the posterior chamber represents an important determinant of the achieved postoperative vault, which is the term used to describe the measurable distance between the anterior capsule of the crystalline lens and the posterior surface of the ICL.

There has been considerable interest in finding ways to improve sizing, ie, the selection of the best-fit overall diameter of ICL for a given eye, because optimal sizing is seen as a way to increase the proportion of ICLs within the range of safe vault. The clinical significance of vault outside of the range of safety resides in the risk of specific adverse events, including pupillary block, anterior subcapsular (ASC) cataract, pigment dispersion and glaucoma. Precise definitions for insufficient vault and excessive vault have, however, remained elusive, because only a percentage of eyes with vault beyond any predefined range experiences vault-related adverse events. While insufficient or excessive vault may be recognized by the occurrence of specific adverse events, eyes with the same degree of vault do not experience these adverse events. Thus, extremes of vault must be viewed as risk factors for adverse events, not as adverse events in and of themselves.

\section{Safe ranges of vault}

Authors have reported a range of values for the limits of safe vault, based on the likelihood that cataract or pupillary block may occur beyond that range. For example, Gonvers et al, ${ }^{16}$ whose study included both the earlier V3 model as well as V4 ICLs, reported in 2003 that:

20 eyes with anterior subcapsular cataracts (ASCCs) had central vaulting equal to or less than $0.09 \mathrm{~mm}$. Among the 55 eyes with clear lenses, 26 had vaulting equal to or less than $0.09 \mathrm{~mm}$ ( 11 of these had no vaulting). ${ }^{16}$

Thus, although vault $\leq 90 \mu \mathrm{m}$ was a risk factor for the development of ASC cataract in this series, the majority of eyes with vault in this range maintained clear lenses.

The authors reported that:

Myopia was more pronounced in the ASCC group: The mean power of the implanted ICLs was $-17.6 \pm 2.9 \mathrm{D}$ (range -11.5 to $-21.0 \mathrm{D}$ ) in the 20 eyes with ASCCs and $-14.9 \pm 3.3 \mathrm{D}$ (range -8.5 to $-20.5 \mathrm{D}$ ) in the 26 eyes with clear lenses. ${ }^{16}$

Therefore, data supported the conclusion that low vault, along with higher levels of myopia, constituted risk factors for ASC cataract (of note, this series included a relatively greater proportion of higher myopia than most others in the literature, with a mean refraction of $-16.5 \pm 3.3 \mathrm{D}$ [range, -8.5 to $-21.0 \mathrm{D}])$.

Gonvers et al ${ }^{16}$ concluded that $150 \mu \mathrm{m}$ should be regarded as a lower limit of safe vault, noting that:

We believe $0.15 \mathrm{~mm}$ in central vaulting should be targeted in future implantations, even though this is greater than the $0.09 \mathrm{~mm}$ vaulting below which (sic) no anterior subcapsular cataracts (ASCCs) were found in our series.

The rationale given for the higher level of central vault was that:

When the central vaulting was equal to or greater than $0.15 \mathrm{~mm}$ (approximately 1.5 the central thickness of the optic), there was no contact (at least up to the midperiphery of the ICL) between the ICL and the crystalline lens regardless of the ICL model. ${ }^{16}$

Schmidinger et al, ${ }^{17}$ whose study also involved earlier V3 as well as V4 model ICLs, reported mean vaulting of $216 \pm 104 \mu \mathrm{m}$ at the initial manifestation of ASC cataract 
and $98 \pm 100 \mu \mathrm{m}$ at the time of cataract extraction. These authors noted a gradual shallowing of vault over time equal to $28 \mu \mathrm{m}$ per year, "close to the mean yearly increase in the crystalline lens rise $(20 \mu \mathrm{m})$." They concluded that "it would be advisable to adhere to a minimum central vaulting of $230 \mu \mathrm{m} . "$

Zeng et $\mathrm{al}^{18}$ suggested a safe range of vault from 100 to $1,000 \mu \mathrm{m}$.

Rayner et $\mathrm{al}^{19}$ reported a "generally accepted" lower limit of $50 \mu \mathrm{m}$, and no specific upper limit, as long as the anterior chamber angle "structure and function remain normal." Bhikoo et $\mathrm{al}^{20}$ initially suggested a lower limit of $200 \mu \mathrm{m}$, but later revised this limit to $150 \mu \mathrm{m}$. In their study of 147 eyes of 80 patients, Lisa et $\mathrm{al}^{21}$ noted that:

[...] eyes with vault values from 100 to $200 \mu \mathrm{m}$ (approximately $8 \%$ ) and from 900 to $1,000 \mu \mathrm{m}$ (approximately $1.5 \%$ ) were followed closely. ${ }^{21}$

Dougherty et $\mathrm{al}^{9}$ suggested a safe range of vault from 90 to $1,000 \mu \mathrm{m}$.

Maeng et $\mathrm{al}^{22}$ retrospectively reviewed charts of 233 eyes of 134 patients implanted with ICLs and found 26 eyes of 20 patients with low vault defined as $250 \mu \mathrm{m}$ or less. They reported cataract development in eight eyes of six patients, representing " $3.4 \%$ of all 233 eyes; $30.8 \%$ of 26 eyes with low vaulting". ${ }^{22}$ Anterior subcapsular cataract was reported in seven of the eight eyes, and cataract surgery was required in five of the eight eyes, a mean of $33.2 \pm 14.3$ months after implantation. ${ }^{22}$

Of note, the vaulting values in the cataract group were statistically significantly lower than in the group without cataract at all follow-up times. The authors concluded that:

The optimum cutoff values that could be used to divide patients into a high-risk group and a low-risk group for cataract development were vault, $51.7 \mu \mathrm{m}$; age 45 years; and preoperative spherical equivalent (SE), $-14.00 \mathrm{D}$ ( $P=0.0095, P=0.0367$, and $P=0.0342$, respectively). ${ }^{22}$

As the foregoing discussion demonstrates, the authors have placed the lower limit of safe vault from approximately 50 to $250 \mu \mathrm{m}$, and the upper limit from approximately $1,000 \mu \mathrm{m}$ upward, as long as the anterior chamber angle structure and function remain normal. These estimates of safe ranges based on the incidence of complications above or below certain thresholds of vault emphasize the conclusion that insufficient or excessive vault should be considered a risk factor, not a complication, and that only a percentage of eyes with vault beyond any predefined range experiences vault-related adverse events.

\section{Biometry}

Selection of ICL size is most commonly based on anatomic measurement of the corneal white-to-white (WTW) horizontal diameter and the anterior chamber depth (ACD). Alternative sizing methodologies employ measurement of the sulcus-to-sulcus diameter (STS), the angle-to angle diameter (ATA), or the iris pigment end-to-pigment end diameter (PTP). The precision and accuracy of the technologies employed in obtaining these measurements should be considered in any discussion of sizing.

WTW is measured with calipers or, more recently, imaging technology such as Scheimpflug photography or scanning slit topography. ${ }^{23,24}$ Methods of measuring WTW include manual calipers and a variety of imaging devices such as Orbscan (Bausch \& Lomb, Rochester, NY, USA), IOL Master (Carl Zeiss Meditec, Jena, Germany), Pentacam (Oculus, Irvine, CA, USA), and Lenstar (Haag Streit, Koeniz, Switzerland). Although automated measurement of WTW is convenient and repeatable, it is not necessarily more accurate than measurement with manual calipers. The various devices use different optical principles for the automatic detection of physical landmarks, so variation in results is not surprising. Validation with manual calipers can help surgeons avoid detection errors due to anomalies in the limbal area such as arcus senilis, pigmentation, pinguecula, and neovascularization, which is particularly common among highly myopic contact lens wearers.

ATA and PTP are measured with optical coherence tomography (OCT). ${ }^{25}$ STS is measured with ultrasound biomicroscopy (UBM). ${ }^{26}$ There have been a number of articles assessing the variance and repeatability of measurements with various UBM devices. For example, Pop et $\mathrm{al}^{27}$ found a standard error of $0.4 \mathrm{~mm}$ and reproducibility of $79 \%$ with $50 \mathrm{MHz}$ UBM. They found that measurement of the sulcus with UBM had greater variation than measurement of WTW with calipers, and concluded that "If precision below $0.4 \mathrm{~mm}$ is required for ICL sizing, UBM may not be the best method of measuring the sulcus."

Oh et $\mathrm{al}^{28}$ found that the coefficient of variation for intraobserver sulcus diameter measurements with $35 \mathrm{MHz}$ UBM was $0.90 \%$, demonstrating "high reliability." However, they measured a vertically oval sulcus shape, in contradistinction to Rondeau et al, ${ }^{29}$ who used a prototype $50 \mathrm{MHz}$ UBM and determined that "the longest diameter 
clusters in the horizontal plane $[\ldots . .$.$] " Rondeau et al { }^{29}$ also found a coefficient of variation of $0.90 \%$, with standard deviation of approximately $100 \mu \mathrm{m}$. Reinstein et $\mathrm{al}^{30}$ reported within-eye repeatability of $0.23 \mathrm{~mm}$ and population standard deviation of $0.69 \mathrm{~mm}$ for sulcus diameter. Guber et $\mathrm{al}^{31}$ utilized the HiScan $35 \mathrm{MHz}$ UBM and found that measures were less repeatable than expected, with a within-subject standard deviation for repeated measures with the same observer $(\mathrm{Sr})$ of $0.39 \mathrm{~mm}$ between any two images and a $95 \%$ confidence interval (CI) of \pm 0.76 . The $\mathrm{Sr}$ improved to $0.15 \mathrm{~mm}$ when the average of two measures was used. Therefore, they concluded, "it is safe to assume that the repeatability is $<0.15$ $\mathrm{mm}$ when the average of four or more images was used." Yokoyama et $\mathrm{al}^{32}$ found a mean coefficient of variation of $0.62 \%$ with the Sonomed $35 \mathrm{MHz}$ UBM.

Although the intraexaminer variance was low in these studies, Yokoyama et $\mathrm{al}^{32}$ also found that interexaminer variance was high. The $95 \% \mathrm{CI}$ of the interexaminer error was -1.09 to $1.52 \mathrm{~mm}$. The authors identified several potential sources of error in these measurements, including misdirection of scanning, contraction of the ciliary muscle, image selection, unclear visualization of the ciliary sulcus, and irregularities in the ciliary sulcus. In conclusion, the authors state, "This amount of variance cannot be ignored in a clinical setting." 32

In general, measurements of WTW, ATA, PTP, and STS do not correlate highly, ${ }^{28,30,33}$ although some authors have found varying degrees of correlation. ${ }^{34}$ These anatomic relationships, while of scientific interest, are only clinically relevant in so far as their utilization may increase the safety of ICL implantation.

\section{Literature review of objectively measured vault: methods}

As noted, ICL sizing and its relationship to achieved ICL vault have generated significant clinical interest. To gain a better understanding of current sizing methodologies and their relationship to achieved vault and complications, we conducted a literature search utilizing two databases, PubMed.gov and Science.gov, using the following search criteria:

- original papers in English published from 2006 to 2015 ,

- prospective or retrospective case series,

- studies utilizing manufacturer recommended sizing nomograms

- studies developing nomograms based on reported clinical data,
- studies reporting data on currently available (ie, V4) Visian ICL models for myopia or myopia and astigmatism,

- studies generally following approved indications for use (eg, ACD $\geq 3 \mathrm{~mm}$ ), and

- studies providing descriptive statistics of objectively measured vault.

Case reports, studies of specific disease entities (eg, keratoconus), case series only presenting vault data for eyes with complications (eg, cataract, elevated intraocular pressure $[\mathrm{IOP}]$ ), and case series only providing vault data for a subset of subjects (eg, those with toric IOL rotation) were excluded.

The search terms were "STAAR" or "Visian" or "phakic ICL" or "implantable ICL" or "phakic implantable collamer lens" or "implantable collamer" or "implantable contact lens" and "vault."

A total of 112 publications were returned and reviewed individually for relevance. In addition, references cited in these publications were examined for potential relevance. Table 1 provides a list of the 22 peer-reviewed, published studies that met the aforementioned criteria, with the sizing methods studied and descriptive statistics of the reported achieved vault.

\section{Reported sizing methodologies}

The studies reporting vault based on WTW and ACD measurements generally employed the manufacturer's sizing nomogram and reported data on a total of 2,263 eyes. The authors' methods state, for example, that "size was determined based on the horizontal WTW distance and ACD, measured with the Orbscan II device following the manufacturer's recommendations"13 or "The ICL diameter was individually determined based on the horizontal WTW distance and ACD measured with Orbscan II (Bausch \& Lomb, Rochester, NY) following the manufacturer's recommendations" 35 or "The size of ICL was also chosen by the manufacturer based on the horizontal corneal diameter and ACD"36 or "The size of the ICL was also chosen by the manufacturer on the basis of the horizontal corneal diameter and the ACD measured by scanning-slit topography (Orbscan IIz)". ${ }^{11}$

Studies employing STS-based sizing reported data on 204 eyes. Authors reported unique nomograms based on regression analysis, for example, "developed using statistical analysis and clinical judgment," or employing a trigonometric formula that included "measurements of ACD and sulcus diameter, the elongation factor of the collamer material, and the base-curve of the ICL model." 37 
Table I Studies with data on objective measurement of ICL vault (chronological order)

\begin{tabular}{|c|c|c|c|c|}
\hline Study & $\begin{array}{l}\mathbf{N} \text { (eyes/ } \\
\text { subjects) }\end{array}$ & $\begin{array}{l}\text { Sizing } \\
\text { method }\end{array}$ & Model & Mean vault microns \pm SD (range) \\
\hline Alfonso et $\mathrm{al}^{38}$ & $452 / 246$ & WTW/ACD & V4 & $4 \mid 4 \pm 228(0-1,300)$ \\
\hline Seo et $\mathrm{al}^{70}$ & $16 / 28$ & WTWIACD & V4 & $440 \pm 330$ \\
\hline Kojima et $\mathrm{a}^{71}$ & $36 / 19$ & WTWIACD & V4 & $530 \pm 250$ \\
\hline Alfonso et $\mathrm{al}^{13}$ & $|88 /| I \mid$ & WTW/ACD & V4 & $364 \pm$ I 98 mm (95\% Cl; 294-434) \\
\hline Dougherty et al ${ }^{9}$ & $73 / 73$ & STS & $\mathrm{MICL}$ & $340 \pm 174(90-952)$ \\
\hline Alfonso et $\mathrm{a}^{35}$ & $133 / 76$ & WTWIACD & V4 & $439 \pm 231(90-910)$ \\
\hline \multirow[t]{2}{*}{ Alfonso et a $7^{72}$} & $323 / 196$ & WTWIACD & V4 & $448 \pm 220(100-1,060)$ \\
\hline & $20 / 196$ & & TICMV4 & $493 \pm 161(260-860)$ \\
\hline \multirow[t]{2}{*}{ Sheng et $\mathrm{a}^{24}$} & $54 / 29$ & WTWIACD & Toric ICL & $322.23 \pm 169.43(48-487)($ feet in sulcus, $n=22)$ \\
\hline & & & & $466.28 \pm 141.12(140-680)$ (feet below sulcus, $n=32)$ \\
\hline Kojima et $\mathrm{al}^{26}$ & $81 / 43$ & STS/STSL & MICL & $640 \pm 250(190-1,330)$ \\
\hline Du et $\mathrm{al}^{36}$ & $127 / 66$ & WTWIACD & V4 & $392 \pm 173$ \\
\hline Reinstein et $\mathrm{al}^{37}$ & $50 / 25$ & STS & $\mathrm{MICL}$ & $370 \pm 160(80-920)$ \\
\hline Alfonso et al ${ }^{65}$ & $138 / 70$ & WTWIACD & V4c & $482.7 \pm 210.5(90-970)$ \\
\hline Higueras-Esteban & $17 / 9$ & WTWIACD & $\mathrm{V} 4 \mathrm{~b}$ & $557 \pm 224(95 \% \mathrm{Cl} ; 442-672)$ \\
\hline et $\mathrm{al}^{67}$ & $18 / 10$ & WTW/ACD & $\mathrm{V} 4 \mathrm{c}$ & $528 \pm 268(95 \% \mathrm{Cl} ; 354-635)$ \\
\hline Cao et $\mathrm{al}^{73}$ & $62 / 31$ & WTWIACD & V4 & $505 \pm 205(149-892)$ \\
\hline \multirow[t]{4}{*}{ Lee et $\mathrm{a}^{74}$} & $54 / 28$ & WTWIACD & V4 & $428.3 \pm 221.9(60-1,090)$ [photopic] \\
\hline & & & & $516.5 \pm 223.7(130-1,230)[$ mesopic] \\
\hline & $56 / 38$ & WTWIACD & V4c & $399.5 \pm 151.9$ (110-960) [photopic] \\
\hline & & & & $547.0 \pm 173.1(210-1,060)$ [mesopic] \\
\hline Ghoreishi and & $63 / 49$ & WTWIACD & V4b & $368.57 \pm|65.66|(100-750)$ \\
\hline \multirow[t]{2}{*}{ Mohammadinia $^{41}$} & & STS & V4b & $365.40 \pm 207.735(|I| 0-1,010)$ \\
\hline & & STS/WTW & $\mathrm{V} 4 \mathrm{~b}$ & $47 I \pm 272.62 I(80-I, 000)$ \\
\hline Alfonso et $\mathrm{al}^{75}$ & $35 / 20$ & WTWIACD & TV4b & $594.3 \pm 155.9(200-810)$ \\
\hline Gomez-Bastar et $\mathrm{al}^{76}$ & $349 / 216$ & WTWIACD & V4/TV4 & $481 \pm 185(100-1,090)$ \\
\hline \multirow[t]{2}{*}{ Kamiya et $\mathrm{al}^{77}$} & $23 / 23$ & WTW/ACD & V4b & $459 \pm 239$ \\
\hline & $23 / 23$ & WTW/ACD & $\mathrm{V} 4 \mathrm{c}$ & $482 \pm 245$ \\
\hline Lisa et $\mathrm{al}^{5}$ & $121 / 68$ & WTWIACD & V4b & $458.2 \pm 217$ \\
\hline Lisa et $\mathrm{al}^{21}$ & $147 / 80$ & WTWIACD & $\mathrm{V} 4 \mathrm{c}$ & $405.5 \pm 184.7(100-980)$ \\
\hline Malyugin et $\mathrm{al}^{25}$ & $29 / 16$ & PTP & MICL & $530 \pm 180(240-840)$ \\
\hline
\end{tabular}

Abbreviations: ICL, implantable collamer lens; SD, standard deviation; PTP, pigment end-to-pigment end diameter; WTW, white-to-white; ACD, anterior chamber depth; STS, sulcus-to-sulcus diameter; MICL, myopia implantable collamer lens; STSL, sulcus-to-sulcus plane to anterior crystalline lens distance.

The single study employing PTP-based sizing included data on 29 eyes and

included 2 stages as follows: (1) comparison of measurements performed by UBM and AS-OCT (suggested new algorithm) and (2) clinical evaluation of the effectiveness of the proposed algorithm for measuring the distance from iris pigment end to iris pigment end..$^{25}$

\section{Meta-analysis of sizing: results}

Comparison of the descriptive statistics for vault reported in the selected studies, as listed in Table 1, demonstrates a great deal of similarity in achieved vault regardless of sizing methodology, and an acceptable range of vault in the vast majority of subjects. For example, the mean vault includes values from 370 to $640 \mu \mathrm{m}$ for STS-based sizing, and from
322 to $594 \mu \mathrm{m}$ for WTW/ACD-based sizing. Standard deviations extend from 160 to $250 \mu \mathrm{m}$ for STS-based sizing, and from 141 to $268 \mu \mathrm{m}$ for WTW/ACD-based sizing. The reported range of vault extends from 0 to $1,300 \mu \mathrm{m}$ for WTW/ACD-based sizing (Alfonso et $\mathrm{al}^{38}$ reported both of these extreme values in their series of 452 eyes). For studies on STS-based sizing, the reported range of vault is 80-1,330 $\mu \mathrm{m}$.

The forest plot provided in Figure 1 demonstrates the variability of vault within and among studies. Achieved vault based on STS and WTW sizing methods are not statistically significantly different (two-sample twosided $t$-test using pooled mean and standard deviations; $t(2,594)=1.33 ; P=0.18)$. The difference in mean (STS minus WTW) is $20 \mu \mathrm{m}$. The $95 \% \mathrm{CI}$ for the difference is -10 to $50 \mu \mathrm{m}$. 
Considering a conservatively safe range of vault from 250 to $1,000 \mu \mathrm{m}$ and assuming a normal distribution of vault, $13 \%$ of STS eyes would have vault between 0 and $250 \mu \mathrm{m}$, and $0.5 \%$ of STS eyes would have vault above $1,000 \mu \mathrm{m}$. Similarly, $16 \%$ of WTW eyes would have vault between 0 and $250 \mu \mathrm{m}$, and $0.4 \%$ of WTW eyes would have vault above $1,000 \mu \mathrm{m}$. Figure 2 provides a graphic representation of the pooled vault data, showing the relative congruence of achieved vault with WTW and STS. In summary, no clinically meaningful or statistically significant difference in achieved vault differentiates WTW- and STS-based sizing methodologies.

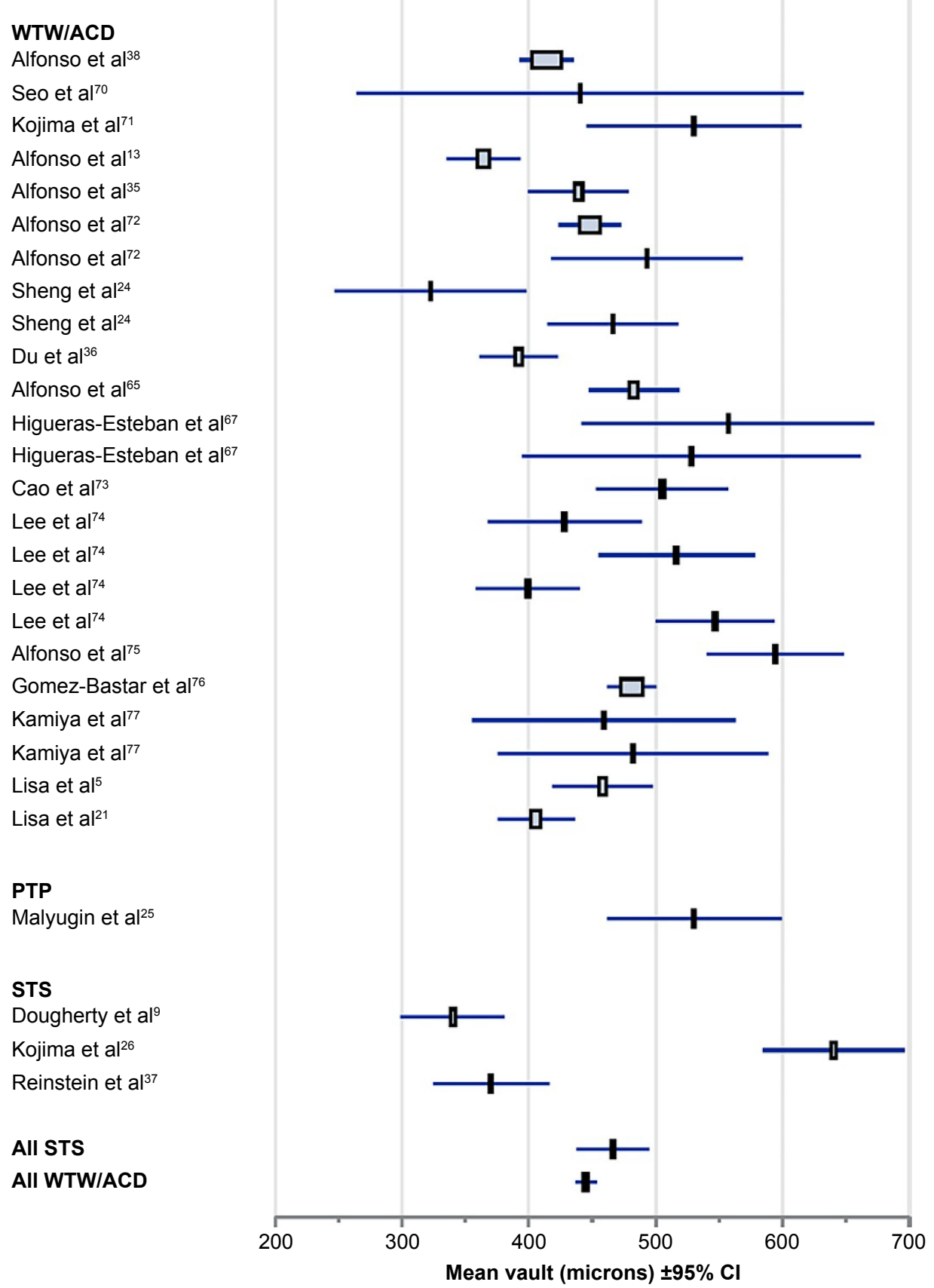

Figure I Forest plot providing means and $95 \% \mathrm{Cl}$ 's for achieved vault in each study.

Notes: The size of the mean bars is proportionate to the number of eyes represented, except for the two summary bars (All STS, All WTW/ACD) at the bottom. Confidence intervals were calculated from the reported means, standard deviations, and sample sizes. The overall standard deviations for the two bottom rows were calculated by pooling the standard deviations from the studies.

Abbreviations: ACD, anterior chamber depth; STS, sulcus-to-sulcus diameter; Cl, confidence interval; PTP, pigment end-to-pigment end diameter; WTW, white-to-white. 


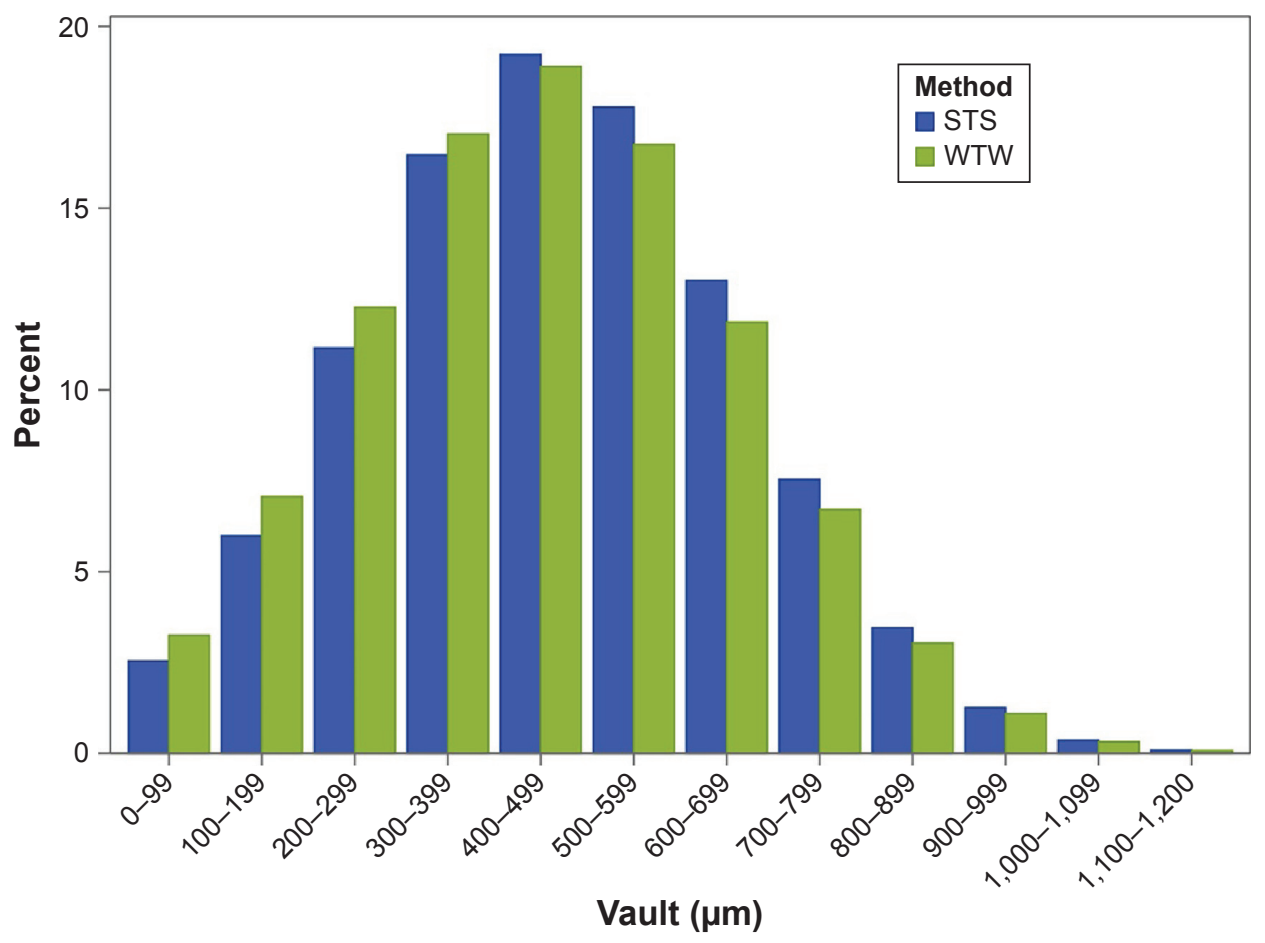

Figure 2 Pooled normal distribution of vault based on means and standard deviations of STS and WTW sizing methods. Abbreviations: STS, sulcus-to-sulcus diameter; WTW, white-to-white diameter.

\section{Critiques of sizing methodology}

A few authors have suggested improved sizing with STS compared to WTW, based on comparisons of clinically measured vault following implantation with STS-based sizing versus theoretical back-calculation of expected vault based on sizing calculated from WTW and ACD. However, the demonstrated variability in achieved vault with all methods of sizing as shown in the published literature appears to render theoretical back-calculation of predicted vault a somewhat questionable methodology.

For example, Reinstein et al ${ }^{37}$ compared achieved vault with STS sizing to the theoretical vault that would have been achieved with WTW sizing using a "gap" constant to represent the distance between the sulcus and the ICL haptic, and reverse circle trigonometry to predict the vault height that would have occurred if a different size lens had been selected. Similarly, Kojima et $\mathrm{al}^{26}$ compared achieved vault to "predicted" vault with WTW sizing (but did not specify the methodology of their prediction). Dougherty et $\mathrm{al}^{9}$ reported the number of times a different size would have been selected with WTW sizing compared with STS sizing. However, the observation that sizing based on STS may produce different results in terms of the recommended ICL diameter compared to sizing based on WTW and ACD does not controvert the evidence that both methods produce very similar means, standard deviations, and ranges of measured postoperative vault.
Lee et $\mathrm{al}^{39}$ examined the relationship of patient age, ICL overall diameter, ICL optical power, and biometric parameters (STS, WTW, K-reading, and ACD) with achieved vault. They concluded,

In the present study, the postsurgical achieved vault could be explained in only approximately $36.9 \%$ of the cases, as determined by multiple regression analysis, which included ICL size, age, and preoperative biometric results, such as STS, as independent variables. ${ }^{39}$

Therefore, as these authors state, the variability of vault regardless of sizing methodology probably reflects unmeasurable ocular characteristics such as "vertical compression by the iris and dampening effect of the ciliary sulcus structure". The demonstrated variability of vault regardless of sizing methodology may be due to unmeasurable anatomic and physiologic factors affecting the relationship of the ICL and the posterior chamber.

Two studies, one by Choi et $\mathrm{al}^{40}$ and another by Ghoreishi et al, ${ }^{41}$ have compared clinical results with STS and WTW sizing. Choi et $\mathrm{al}^{40}$ reported a small retrospective study in which sizing based on STS was compared with sizing based on WTW; however, this study could not be included in the meta-analysis because the authors did not report descriptive statistics of vault, reporting instead the numbers of cases within "the ideal range $(250-750 \mu \mathrm{m})$." Because the 
UBM device utilized by these authors gave only a partial view of the sulcus, the STS distance was determined by first creating physical epithelial dimples on the limbus at 3 o'clock and 9 o' clock that could be imaged with ultrasound. An imaginary vertical (ie, paraxial) line was then drawn on the ultrasound image from each dimple to the posterior iris pigment epithelium. The horizontal (ie, coronal) distances from this line to the ciliary sulcus at 3 o'clock and 9 o'clock were added to the WTW as measured by Orbscan or caliper. Using this method, 13 of 13 eyes achieved vault within the ideal range; however, utilizing only WTW, nine of 17 eyes achieved ideal vault. One eye in the WTW group underwent ICL exchange for insufficient vault $(90 \mu \mathrm{m})$ at 6 months postoperatively.

Ghoreishi and Mohammadinia ${ }^{41}$ prospectively compared vault based on randomization to sizing based on either WTW ("WTW value was entered into the ICL calculation formula which was proposed by the manufacturer") or STS ("ICL size was ordered based on horizontal sulcus-to-sulcus measurement"). In a third, nonrandomized group, sizing was based on an average of WTW and STS ("M group"). The mean, standard deviation, and range of vault in the WTW group were $368.57 \pm 165.661 \mu \mathrm{m}$ (range, 100-750 $\mu \mathrm{m}$ ), while in the STS group they were $365.40 \pm 207.735 \mu \mathrm{m}$ (range, 110-1,010 $\mu \mathrm{m}$ ) and in the third group they were $411.43 \pm 217.21 \mu \mathrm{m}$ (range, 80-1,010 $\mu \mathrm{m}$ ).
In the WTW group, 77\% of eyes had acceptable or ideal vault according to the authors' criteria, compared with $76 \%$ in the STS group. In the third group, only $40 \%$ had acceptable or ideal vault; however, there were no statistically significant differences in achieved vault among the three groups.

Ghoreishi and Mohammadinia ${ }^{41}$ concluded,

[...] STS measurement, by itself, did not improve the ICL

sizing results in our study. ${ }^{41}$

In sum, Ghoreishi and Mohammadinia, ${ }^{41}$ in their randomized prospective study, reported no clinically meaningful nor statistically significant difference in achieved vault between WTW- and STS-based sizing methods.

While the quest for improved predictability of vault based on different imaging technologies may appear to represent an appealing endeavor, it has not resulted in a demonstrable reduction in the variability of achieved vault or in the already low rate of complications that occur following ICL implantation. Those studies included in the literature review that specifically reported complications, including studies utilizing WTW/ACD, STS, and/or PTP methodologies, included data from 1,387 eyes followed for up to 10 years. The overall rate of secondary surgical intervention was $0.8 \%$ (Table 2 ), indicating a low rate of complications. Replacement of the ICL was performed in

Table 2 Studies with objective data on vault also reporting safety outcomes

\begin{tabular}{|c|c|c|c|c|c|c|c|}
\hline Study & $\mathbf{N}$ (eyes) & Length of follow-up & $\begin{array}{l}\text { ICL removal, } \\
\text { replacement, } \\
\text { reposition } \% \text { ( } N \text { eyes) }\end{array}$ & $\begin{array}{l}\text { ASC } \\
\text { opacities } \\
\% \text { ( } \mathbf{N} \text { eyes) }\end{array}$ & $\begin{array}{l}\text { Cataract } \\
\text { surgery \% } \\
\text { ( } \mathrm{N} \text { eyes) }\end{array}$ & $\begin{array}{l}\text { Pupillary } \\
\text { block \% } \\
\text { (N eyes) }\end{array}$ & $\begin{array}{l}\text { Ocular hypertension } \\
\text { or glaucoma } \% \\
\text { ( } \mathbf{N} \text { eyes) }\end{array}$ \\
\hline Seo et $\mathrm{al}^{70}$ & 16 & $\begin{array}{l}19.75 \pm 17.14 \text { months } \\
\text { (range: } 6-56 \text { months) }\end{array}$ & NR & NR & 0 & NR & NR \\
\hline Kojima et $\mathrm{al}^{71}$ & 36 & I year & 0 & 0 & 0 & 0 & 0 \\
\hline Alfonso et $\mathrm{al}^{13}$ & 188 & 5 years & 0 & I.I (2) & $0.5(I)$ & 0 & 0 \\
\hline Sheng et $\mathrm{al}^{24}$ & 54 & $\begin{array}{l}8.6 \pm 4.6 \text { months } \\
\text { (range: } 3-20 \text { months) }\end{array}$ & $3.7(2)$ & 0 & 0 & 0 & 0 \\
\hline Kojima et $\mathrm{al}^{26}$ & 81 & 3 months & 0 & 0 & 0 & 0 & 0 \\
\hline Reinstein et $\mathrm{al}^{37}$ & 50 & $\begin{array}{l}6.5 \pm 0.7 \text { years } \\
\text { (range: } 4.1-7.4 \text { years) }\end{array}$ & 0 & $4.0(2)$ & 0 & 0 & NR \\
\hline Alfonso et $\mathrm{al}^{65}$ & 138 & 6 months & 0 & 0 & 0 & 0 & 0 \\
\hline $\begin{array}{l}\text { Higueras- } \\
\text { Esteban et al }{ }^{67}\end{array}$ & 35 & 3 months & NR & NR & NR & 0 & 0 \\
\hline Cao et $\mathrm{al}^{73}$ & 62 & 3 months & 0 & NR & 0 & 0 & 0 \\
\hline Alfonso et $\mathrm{al}^{75}$ & 35 & I year & 0 & 0 & 0 & 0 & 0 \\
\hline $\begin{array}{l}\text { Gomez-Bastar } \\
\text { et } \mathrm{al}^{76}\end{array}$ & 349 & $\begin{array}{l}47 \pm 31 \text { months } \\
\text { (range: } 3-127 \text { months) }\end{array}$ & I.2 (4) & 0 & 0 & 0 & 0 \\
\hline Kamiya et $\mathrm{al}^{77}$ & 46 & I year & 0 & 0 & 0 & 0 & 0 \\
\hline Lisa et $\mathrm{al}^{5}$ & 121 & I year & 0 & 0 & 0 & 0 & 0 \\
\hline Lisa et $\mathrm{al}^{21}$ & 147 & I year & 0 & 0 & 0 & 0 & 0 \\
\hline Malyugin et $\mathrm{al}^{25}$ & 29 & I year & 0 & 0 & 0 & 0 & 0 \\
\hline Total N & $\mathrm{I}, 387$ & & $0.4(6)$ & $0.3(4)$ & $0.1(1)$ & 0 & 0 \\
\hline
\end{tabular}

Abbreviations: ICL, implantable collamer lens; ASC, anterior subcapsular; NR, not reported. 
six eyes $(0.4 \%)$, asymptomatic ASC cataracts were observed in four eyes $(0.3 \%)$, and cataract surgery was performed in one eye $(0.1 \%)$. There were no reported cases of pupillary block or glaucoma.

In summary, no methodology has proven superior in terms of the predictability of vault to the use of WTW and ACD, which remains the most popular and best-studied technique.

\section{Complications of ICL implantation}

Several authors who did not report descriptive statistics for objective vault and whose work was therefore excluded from the meta-analysis have, however, reported rates of secondary surgical intervention related to insufficient vault in the presence or absence of cataract formation, and excessive vault in the presence or absence of elevated IOP, and therefore merit inclusion in this review.

\section{ICL replacement}

In their study of lens exchange, Zeng et a ${ }^{18}$ adopted criteria for exchange as follows: vault less than $100 \mu \mathrm{m}$ or direct contact between the ICL and the crystalline lens; or vault greater than 1,000 $\mu \mathrm{m}$ and shallow anterior chamber with angle closure in any quadrant, or vault greater than $1,000 \mu \mathrm{m}$ without angle closure but pupil diameter larger than preoperative and unrelieved patient-reported glare.

In a cohort of 616 eyes of 337 patients implanted with ICLs sized according to WTW and ACD measurements, 16 eyes of 15 patients $(2.6 \%)$ met the authors' criteria for lens replacement. Of these 16 replacements, eight were indicated for insufficient vault, while eight were indicated for excessive vault.

For comparison, in the US FDA investigational device study of the Visian ICL, in which sizing was also performed based on WTW and ACD, although criteria for surgical intervention may have differed, ICL replacement for insufficient or excessive vault was reported in five of 526 eyes (1.0\%): "Two (0.4\%) ICLs were replaced, because they were too long (at 2 and 3 days postoperatively); two (0.4\%) ICLs were replaced because they were too short (at 3 weeks and 17 months)" and "one ( $0.2 \%)$ ICL was replaced for a longer lens (at 26 months postoperatively)." ${ }^{\circ 2}$ The small proportion of eyes with either insufficient or excessive vault in both the study by Zeng et $\mathrm{al}^{18}$ and the US FDA report were similar, suggesting that the sizing nomogram appropriately targets the median.

Rayner et a ${ }^{19}$ reported replacing ICLs, which had been sized using WTW and ACD, in two of 126 eyes of 68 patients
(1.6\%) for excessive vault on the basis of somewhat different criteria from those of Zeng et al: ${ }^{18}$

Generally accepted limits of ICL vaulting are around $50 \mu \mathrm{m}$ (just visible gap), and no specific upper limit as long as angle structure and function remains normal. ${ }^{19}$

Bhikoo et $\mathrm{al}^{20}$ used WTW and ACD for sizing the Toric ICL (TICL), and noted,

Anterior chamber depth and horizontal limbal 'white-towhite' distances were measured with the Orbscan corneal topographer. A variety of alternative technologies can also be used to determine these measurements - there is no agreement as to the optimal technology to use. ${ }^{20}$

These authors replaced one ICL for "low vault" of $180 \mu \mathrm{m}$ out of 72 eyes operated (1.4\%). The authors noted that they subsequently changed their criterion for replacement to vault $<150 \mu \mathrm{m}$.

In summary, ICL exchange for insufficient or excessive vault in the absence of complications remains a matter of medical judgment. On the other hand, excessive vault in the presence of compromised anterior chamber angle function and insufficient vault in the presence of visually significant cataract are indications for surgical intervention.

\section{Cataract}

Several authors whose work was excluded from the literature review of objective vault have provided additional data regarding the development of cataract following ICL implantation. For example, Lee et $\mathrm{al}^{12}$ reported data on 281 eyes of 145 patients who underwent ICL implantation and had follow-up of at least 5 years ( $87 \pm 18.9$ months). Their paper was excluded from the literature review because they did not provide objective measurement of postoperative vault, using instead the commonly applied clinical method of classifying vault into five levels by comparing the separation between the anterior surface of the crystalline lens and the posterior surface of the ICL to the corneal thickness using an optical section during routine slit-lamp examination. Six eyes $(2.1 \%)$ developed asymptomatic ASC cataracts that had not required cataract surgery by the last visit, in which one eye $(0.3 \%)$ showed no change in best corrected logMAR visual acuity (BCVA) and five eyes (1.8\%) lost two lines. Although no eye required cataract surgery, the patients were scheduled for closer follow-up.

In a large retrospective study, Alfonso et a ${ }^{143}$ reported on 3,420 eyes of 1,898 patients who underwent implantation with the ICL V4, V4b, or V4c (V4 and V4b have similar 
designs, differing only in storage solution, ie, sodium chloride or balanced salt solution); follow-up varied from $6 \pm 2$ years (range, 1-12 years) to 2.0 \pm 0.5 years (range, $1-3$ years) and to $6 \pm 4$ months (range, 3-24 months), respectively. Twentyone eyes $(0.61 \%)$ had explantation for ASC cataract, and the mean time between ICL implantation and cataract surgery was $4.2 \pm 1.8$ years (range, $1-7$ years). Although the authors did not provide descriptive statistics for vault in the entire population (and, therefore, their paper was excluded from the literature review), they did note that:

The mean vault in eyes that developed cataracts was $103 \pm 69 \mu \mathrm{m}$ (range 40 to $270 \mu \mathrm{m}$ ); in 15 eyes $(70 \%)$ the vault was less than $100 \mu \mathrm{m}$, and in 6 eyes (30\%) the vault was between $100 \mu \mathrm{m}$ and $270 \mu \mathrm{m}$.

In their 5-year retrospective study, Brar et $\mathrm{al}^{44}$ reported that, out of a total of 957 eyes, four eyes $(0.4 \%)$ had explantation for ASC cataract, and an additional four eyes $(0.4 \%)$ had explantation for nuclear or posterior subcapsular cataract. Thus, 50\% of cataracts were not related to the ICL. Mean time between ICL implantation and cataract surgery was $65.5 \pm 24.1$ months. Although the authors did not report descriptive statistics for vault for their entire subject population, they did note that six eyes $(0.6 \%)$ had ICL exchange for excessive vault, and five eyes $(0.5 \%)$ had ICL exchange for frequent rotation of a toric lens, which was associated with insufficient vault.

Igarashi et $\mathrm{al}^{11}$ reported on 41 eyes implanted with the V4 ICL after 8 years of follow-up. While four eyes $(9.8 \%)$ developed asymptomatic ASC cataracts, an additional four eyes $(9.8 \%)$ developed asymptomatic nuclear cataracts, which are unrelated to the ICL. Two eyes (4.9\%) had explantation for cataract; however, the authors did not specify the type of cataract present in these cases. The relatively older age of subjects at the time of implantation in the study by Igarashi et al $^{11}$ (37.3 \pm 10.2 years, range, $21-55$ years) likely predisposed them to a higher incidence of cataract.

In fact, baseline age was a risk factor for cataract development in the US FDA investigational study of the ICL. ${ }^{8}$ Of 209 eyes of subjects $\geq 40$ years at the time of ICL implantation, six (2.9\%) developed clinically significant cataracts by 5 years postoperative. In contrast, cataract developed in only one $(0.3 \%)$ of the 317 eyes of subjects $<40$ years of age $(P<0.02$ with Fisher's exact test). These findings support the conclusion that cataract also occurs more frequently following ICL implantation in patients of older age.

The association of increasing cataract with age is expected, with very large relative risk found with advancing age in multiple epidemiological studies. ${ }^{45-48}$ The overall frequency of visually significant cataract in the worse eye of patients without a history of intraocular surgery aged $43-54$ has been reported as $1.6 \%(2.6 \%$ in women and $0.4 \%$ in men $){ }^{49}$

Schmidinger et $\mathrm{al}^{17}$ noted the association of insufficient vault with ASC cataract, and described a $17 \%$ rate of cataract surgery after 10 years of follow-up. This relatively high rate of cataract may be related to the higher degree of myopia treated by these authors, who reported a mean spherical equivalent of $-16.4 \pm 5.4 \mathrm{D}$ (range, -5.5 to $-29.0 \mathrm{D}$ ) among eyes of subjects implanted with the V4 ICL $(n=84)$. Long-term follow-up by other authors suggests that higher myopia is a risk factor for the development of visually significant cataract following ICL implantation. Of note, high myopia is also a risk factor for cataract in patients without any history of intraocular surgery.

Gonvers et al, ${ }^{16}$ who used earlier model ICLs, first reported in 2003 that

[...] myopia was more pronounced in the ASCC group: The mean power of the implanted ICLs was $-17.6 \pm 2.9 \mathrm{D}$ (range -11.5 to $-21.0 \mathrm{D}$ ) in the 20 eyes with ASCCs and $-14.9 \pm 3.3 \mathrm{D}$ (range -8.5 to $-20.5 \mathrm{D}$ ) in the 26 eyes with clear lenses. ${ }^{16}$

With regard to the incidence of cataract reported by Gonvers et al, ${ }^{16}$ it is relevant to note the relatively low mean vault described at 3 months postoperative for the $51 \mathrm{~V} 4$ ICLs implanted in their study, "mean $0.12 \pm 0.11 \mathrm{~mm}$; range 0 to $0.37 \mathrm{~mm}$." The low mean vault explains the relatively higher frequency of eyes with ASC opacities reported in this study, 27\% with follow-up of $24 \pm 7$ months (range, 12-34 months). These data support the conclusion that low vault, together with higher levels of myopia, constitute risk factors for ASC cataract.

Sanders ${ }^{8}$ also reported the association of higher myopia with the development of visually significant ASC cataract based on data from the postapproval continuation of the Visian ICL clinical study. He noted that while the mean preoperative spherical equivalent refraction of seven eyes that developed clinically significant cataracts was $-16.40 \mathrm{D}$ (range, -12.75 to $-20.00 \mathrm{D}$ ), the mean spherical equivalent of the entire cohort $(\mathrm{n}=526)$ was $-10.10 \mathrm{D}$ (range, -3.00 to $-20.00 \mathrm{D})$. Additionally, while clinically significant cataracts occurred in seven $(6.6 \%)$ of 106 eyes with preoperative myopia of $-12.00 \mathrm{D}$ or higher, none occurred in the 420 eyes with preoperative myopia lower than $-12.00 \mathrm{D}(P<0.0001$ with Fisher's exact test). These data support the conclusion that cataract occurs more frequently in patients with a higher degree of myopia at baseline. 
Of note, other types of cataract have also been shown to occur more frequently in the setting of higher myopia. Although the association of myopia with nuclear cataract is confounded by the increased index of refraction of the lens, preexisting myopia related to axial length has been associated with an increased incidence of nuclear and posterior subcapsular cataract at an earlier age. ${ }^{50-52}$ In particular, posterior subcapsular cataract has been associated with deeper anterior chamber, thinner lens, and a longer vitreous chamber. ${ }^{53}$ The 10 -year incidence of cataract surgery among patients with moderate-to-high myopia ( $-3.5 \mathrm{D}$ or higher) has been reported as $22 \%$ in a population aged $\geq 49$ years. ${ }^{54}$ For comparison, the rate among emmetropes in the same population was $9.2 \%$. Potential mechanisms leading to early cataract in high myopia are largely undetermined, but some have hypothesized that retinal lipid peroxidation might play a key role. ${ }^{55}$

Guber et a ${ }^{56}$ recently reported data from a cohort of 133 eyes of 78 patients, of which 75 eyes (56.4\%) from 45 patients were examined 10 years after ICL implantation:

The rate of lens opacity development was $40.9 \%$ (95\% CI,

$32.7 \%-48.8 \%$ ) and $54.8 \%(95 \% \mathrm{CI}, 44.7 \%-63.0 \%)$ at 5 and

10 years, respectively. ${ }^{56}$

The authors note that the relatively high incidence of lens opacities observed may have been related to their use of Scheimpflug photography and "full dilation." On the other hand, the relatively higher incidence of cataract surgery reported in this study may be related primarily to older age and higher myopia. Twenty-five percent of the subjects in Guber's study were over 45 at the time of ICL implantation, and $50 \%$ of the subjects had greater than $-12 \mathrm{D}$ of myopia.

Unfortunately, Guber et $\mathrm{al}^{56}$ did not report the types of lens opacities that developed nor the types of cataracts that required surgery. In other studies, eg, those published by Igarashi et $\mathrm{al}^{11}$ and Brar et al, ${ }^{44}$ nuclear sclerosis and posterior subcapsular cataract - unrelated to the ICL - are noted to account for half of asymptomatic lens opacities or visually significant cataracts in patients implanted with the ICL. Therefore, the true rate of cataract surgery secondary to ICL implantation in the cohort reported by Guber et $\mathrm{al}^{56}$ remains uncertain.

Table 3 summarizes information on the incidence of lens opacities and cataract surgery from long-term studies of ICL implantation. In the context of these ten publications, which present data on 5,477 eyes followed for up to 10 years, the relatively higher incidences of opacities and cataract surgery in the reports by Schmidinger ${ }^{17}$ and $\operatorname{Guber}^{56}(n=159)$ appear to represent outliers. Excluding these reports, the incidence of ASC opacities ranges from $1.1 \%$ to $5.9 \%$, and the incidence of ASC cataracts requiring surgery ranges from $0 \%$ to $1.8 \%$. Higher myopia in Schmidinger et al, ${ }^{17}$ and a relatively older population and higher myopia in Guber et al, ${ }^{56}$ may help explain their higher rates of reported lens opacities and cataracts.

\section{Pigment dispersion glaucoma}

As listed in Table 2, there was a zero incidence of pigment dispersion, ocular hypertension, or glaucoma reported in the publications included in the meta-analysis of vault. Pigment dispersion glaucoma has generally been considered to be related to excessive vault; however, Guber et $\mathrm{al}^{56}$ noted normal vault ("403 $\mu \mathrm{m}$ on a mean of $190-740 \mu \mathrm{m}$ [sic]") among "16 cases of ocular hypertension controlled with IOP-lowering treatment, developing a mean of 7.3 years (range, 1.4-12 years) after implantation." 56 These cases were associated with pigmentation "observed in the iridocorneal angle;" however, the authors did not specify whether

Table 3 Studies reporting long-term data on incidence of lens opacities and cataract surgery

\begin{tabular}{|c|c|c|c|c|c|c|c|c|c|c|c|}
\hline \multirow[t]{2}{*}{ Study } & \multirow{2}{*}{$\begin{array}{l}\mathbf{N} \text { (eyes/ } \\
\text { subjects) }\end{array}$} & \multirow[t]{2}{*}{ Follow-up } & \multicolumn{4}{|c|}{ Opacities \% ( $\mathbf{N}$ eyes) } & \multicolumn{4}{|c|}{ Surgical cataracts \% ( $\mathbf{N}$ eyes) } & \multirow[t]{2}{*}{ Comments } \\
\hline & & & ASC & NS & PSC & NR & ASC & NS & PSC & NR & \\
\hline Sanders ${ }^{8}$ & $3 \mathrm{II} / \mathrm{NR}$ & 7 years & $5.9(3 \mathrm{I})$ & (5) & 0 & 0 & $1.3(7)$ & 0 & 0 & 0 & \\
\hline Kamiya et al ${ }^{78}$ & $56 / 34$ & 4 years & II (6) & 0 & 0 & 0 & $1.8(1)$ & 0 & 0 & $1.8(\mathrm{I})$ & Traumatic cataract: I eye \\
\hline Schmidinger et $\mathrm{al}^{17}$ & $84 / 84$ [V4 ICL] & 6 years & 28 & 0 & NR & 0 & 17 & 0 & NR & 0 & Higher myopia \\
\hline Alfonso et $\mathrm{al}^{13}$ & $|88 /|||$ & 5 years & I.I (2) & 0 & 0 & 0 & $0.5(I)$ & 0 & 0 & 0 & \\
\hline Igarashi et al"I & $4 I / 4 I$ & 8 years & $9.8(4)$ & $9.8(4)$ & 0 & 0 & NR & NR & NR & $4.9(2)$ & $50 \%$ unrelated to $\mathrm{ICL}$ \\
\hline Lee et $\mathrm{al}^{12}$ & $28 I / / 45$ & 7 years & $2.1(6)$ & 0 & 0 & 0 & 0 & 0 & 0 & 0 & \\
\hline Alfonso et $\mathrm{al}^{43}$ & $3,420 / 1,898$ & 6 years & NR & NR & NR & 0 & $0.61(2 I)$ & $0.03(\mathrm{I})$ & $0.09(3)$ & 0 & Combined cataracts: 4 eyes \\
\hline Brar et $\mathrm{al}^{44}$ & $957 / N R$ & 5 years & NR & NR & NR & 0 & $0.4(4)$ & $0.2(2)$ & $0.2(2)$ & 0 & $50 \%$ unrelated to $\mathrm{ICL}$ \\
\hline Guber et $\mathrm{al}^{56}$ & $75 / 45$ & 10 years & NR & NR & NR & 54.8 & $N R$ & NR & NR & 18.3 & Higher myopia, older age \\
\hline Shimizu et $\mathrm{al}^{63}$ & $64 / 32$ & 5 years & $3.2(1)$ & 0 & 0 & 0 & 0 & 0 & 0 & 0 & \\
\hline
\end{tabular}

Abbreviations: NR, not reported; ICL, implantable collamer lens; ASC, anterior subcapsular; PSC, posterior subcapsular cataract; NS, nuclear sclerosis. 
the pigmentation was noted to increase over time, or was different from pigmentation observed in eyes without ocular hypertension. They concluded, "To our knowledge, to date, cases of ocular hypertension requiring treatment have not been discussed, making comparison impossible." However, Sanders et $\mathrm{al}^{4}$ reported two eyes out of $526(0.4 \%)$ with increased IOP requiring treatment at 3 years postoperative. In the context of ICL implantation, it is important to remember that myopia alone is a well-established risk factor for glaucoma. ${ }^{57}$

\section{Endothelial cell loss}

Corneal health has remained an important long-term safety concern for patients undergoing intraocular procedures, although its relationship to ICL vault is unknown. Several long-term studies have provided information on endothelial cell density (ECD) following ICL implantation.

Moya et al $^{58}$ have published a cumulative 12-year retrospective study including data from 144 eyes implanted with ICLs between 1998 and 2001. Given the long period of follow-up, to avoid bias due to

[...] variability of the population attending a particular follow-up visit, it was not the mean ECD at each visit that was considered but rather the mean of the intra-subject variation of ECD considering each period of study.

Preoperative, first year, and last visit mean ECD were 2,586.61 $\pm 320.14,2,434.13 \pm 290.12$, and 2,071.13 \pm 361.84 cells $/ \mathrm{mm}^{2}$, respectively (Kruskal-Wallis test, $P<0.05$ ). There were no corneal adverse events during the course of follow-up. The authors conclude,

[...] we can estimate a $6.46 \%$ surgically induced ECD decrease during the first year and an average yearly decrease rate of $1.20 \%$ after that.

The authors go on to state that a 30-year-old patient with a preoperative

[...] ECD of 2,586 cells $/ \mathrm{mm}^{2}$ (mean preoperative value for age-matched patients included in our study) who had ICL implantation would reach 1,500 cells $/ \mathrm{mm}^{2}$ (the threshold value below which explantation is recommended) at the age of 70 years (ie, 40 years after implantation).

In a separate long-term study, Igarashi et $\mathrm{al}^{11}$ reported 8 -year follow-up on 41 eyes of 41 patients. They reported,

The mean percentage of endothelial cell loss was $6.2 \pm 8.6 \%$ $(-24.5 \%$ to $22.8 \%) 8$ years postoperatively.
There were no corneal adverse events reported. The authors commented,

In the current study, the mean percentage of endothelial cell loss was $6.2 \% 8$ years postoperatively, which was considerably lower than the findings in previous studies.

Five year follow-up, reported by Alfonso et al, ${ }^{13}$ demonstrated that the mean ECD decreased from 2,698 \pm 467 cells/ $\mathrm{mm}^{2}$ preoperatively to $2,495 \pm 357$ cells $/ \mathrm{mm}^{2}$, representing a mean endothelial cell loss of $7.5 \%$. The availability of long-term data from these studies is reassuring regarding the corneal health of patients implanted with the ICL.

\section{Management of excessive or insufficient vault and related complications}

Close observation of ICLs with insufficient or excessive vault represents an important mitigation of vault-related adverse events, including cataract and glaucoma. However, given the variety of criteria and recommendations in the literature for the acceptable limits of vault, the decision to initiate close observation or replace an ICL due to insufficient or excessive vault in the absence of vault-related complications remains a matter of medical judgment. Furthermore, the development of ASC cataract, pigment dispersion, or elevated IOP not requiring treatment or amenable to treatment with topical medication does not in and of itself represent an indication for replacement or explantation, because "Some eyes with stable peripheral ASCC may never experience a loss of bestcorrected visual acuity", ${ }^{17}$ and IOP monitoring will address the "theoretical risk of pigmentary glaucoma" that "has not been realized yet." ${ }^{19}$ As an example of the stable, nonvisually significant nature of many ASC opacities, Sanders ${ }^{8}$ concluded that while approximately $6 \%-7 \%$ of eyes developed ASC opacities at 7+ years following ICL implantation, only $1 \%-2 \%$ progressed to clinically significant cataract during the same period.

While precise, objective measurement of vault with OCT is useful for research, for clinical purposes subjective slit lamp evaluation of postoperative vault (eg, using corneal thickness as a measure) is generally adequate to determine both the need for close follow-up and the indication for replacement. As Alfonso et a ${ }^{13}$ have demonstrated,

Subjective and objective values of vault are highly correlated [...]. There was a statistically significant high correlation between subjective and objective values (Spearman rho; $r=0.82 ; P<0.001$ ). 
Nevertheless, it is important to take into account both illumination and accommodation, which may impact the observed vault at any given time.

Reported outcomes following ICL replacement, although limited in number, support the utility of this procedure. Zeng et al, ${ }^{18}$ for example, reported normalization of vault without concomitant morbidity in all 16 eyes undergoing replacement in their study:

$[\ldots]$ there were no surgical complications, such as significant endothelial cell loss or cataracts, after the pIOL exchange in our study.

Explantation is indicated in the setting of progressive, visually significant cataract, whether or not ICL related. Reports of ICL explantation, phacoemulsification cataract extraction, and posterior chamber intraocular lens implantation support the utility of this procedure. As Sanders ${ }^{8}$ noted in his report, "Anterior Subcapsular Opacities and Cataracts 5 Years After Surgery in the Visian Implantable Collamer Lens FDA Trial,"

\section{[...] postoperative BSCVA compared to BSCVA before}

ICL implantation improved by 2 lines in 1 eye, 1 line in

3 eyes, and was unchanged in the remaining 3 eyes for an

average improvement of 0.7 lines of BSCVA.

Kamiya et a $\mathrm{l}^{59}$ reported on a series of ten eyes of eight patients who underwent ICL explantation and cataract surgery 3.6 \pm 1.9 years (range, 1.6-7.4 years) after ICL implantation. One eye showed no change in best spectacle corrected visual acuity, two eyes gained 1 line, seven eyes gained 2 or more lines, and no eyes lost any lines. No adverse events, including increased IOP, posterior capsular opacity, cystoid macular edema, or retinal detachment, were seen at any time during the 3-month follow-up period. Regarding ICL explantation and cataract surgery, it should be noted that virtually all implanted ICLs will one day be explanted in the setting of age-related cataract, given the life expectancy and incidence of cataracts in the population of patients who are candidates for ICL implantation today. Fortunately, the results of cataract surgery in the setting of prior ICL implantation mirror the successful outcomes of today's routine cataract surgery.

\section{V4c Visian ICL with KS Aquaport, VICMO}

The VICMO ICL, which is currently available outside the United States, is a single-piece lens designed with a central convex/concave optical zone of 4.9 or $5.8 \mathrm{~mm}$ diameter and a $360 \mu \mathrm{m}$ center optic port. The lens also contains four other $360 \mu \mathrm{m}$ through-ports, two at the alignment marks (one at either side of the optic) and two on the footplates (one on the leading right haptic and one on the trailing left haptic). These ports are intended to facilitate removal of viscoelastic during surgery, reducing the risk of postoperative increases in IOP. In addition, the orientation holes on the right leading and left trailing foot plates have been enlarged from 110 to $360 \mu \mathrm{m}$ to improve visualization of the holes and better aid lens orientation.

As with all Visian ICL models, the VICMO lens is produced from Collamer, a proprietary hydroxyethyl methacrylate/porcine-collagen-based biocompatible polymer material and an ultraviolet-absorbing chromophore. It has a refractive index of 1.442 at room temperature in balanced salt solution. The ICL is designed as a plate haptic lens with a central anterior convex surface with a concave posterior surface. The lens incorporates a forward vault designed to minimize contact with the central anterior capsule of the human crystalline lens. All Visian ICL models are capable of being folded and implanted through an incision of $3.5 \mathrm{~mm}$ or less.

In a preclinical study performed by Fujisawa et al, ${ }^{60}$ 20 eyes of ten 3-month old miniature pigs were implanted with ICL lenses and the anterior segments were photographed at 1 week, 1 month, and 3 months after surgery. Evans Blue was infused into the vitreous at 3 months and then the eyes were enucleated, fixed, and examined. In the ICL without holes, ASC opacities were observed in all eyes, and the anterior surfaces of the crystalline lenses were not stained. Implantation of the ICLs with $3.0 \mathrm{~mm}$ holes resulted in light staining of the anterior surface of the lens. In these eyes, no subcapsular opacities were observed.

Shiratani et al ${ }^{61}$ confirmed these findings in their study of ICLs with $1.0 \mathrm{~mm}$ central holes, noting that:

Unperforated ICLs cause cataracts, but placing a hole in the center of the optic appears to prevent the development of a secondary cataract. [...] The mechanism of cataract prevention is considered to be related to the aqueous humor circulation. ${ }^{61}$

The VICMO ICL has been available in markets outside of the United States since 2011. Peer-reviewed scientific publications reporting overall clinical safety and effectiveness data following VICMO implantation are listed in Table 4. Each of these studies employed sizing methodology based on WTW and ACD measurements. Of note, the difference between vault of the $\mathrm{V} 4 \mathrm{c}$ and other models without the central port, based on the publications listed in Table 1, is not statistically 
Table 4 Publications reporting overall safety and effectiveness data for V4c with KS Aquaport, VICMO

\begin{tabular}{|c|c|c|c|}
\hline Study & $\begin{array}{l}\text { N V4c } \\
\text { eyes }\end{array}$ & $\begin{array}{l}\text { N V4c } \\
\text { patients }\end{array}$ & Design \\
\hline Shimizu et al $^{79}$ & 20 & 20 & Retrospective case series \\
\hline Shimizu et $a^{68}$ & 29 & 29 & Prospective comparison \\
\hline Alfonso et $\mathrm{a}^{65}$ & 138 & 70 & Prospective case series \\
\hline Kamiya et al ${ }^{69}$ & 28 & 28 & Retrospective comparison \\
\hline Higueras-Esteban et al ${ }^{67}$ & 18 & 10 & Retrospective comparison \\
\hline Gonzalez-Lopez et al ${ }^{66}$ & 100 & 56 & Retrospective case series \\
\hline Huseynova et al ${ }^{64}$ & 44 & 44 & Retrospective comparison \\
\hline Kamiya et a ${ }^{77}$ & 23 & 23 & Retrospective comparison \\
\hline Alfonso et $\mathrm{al}^{43}$ & 781 & NR & Retrospective comparison \\
\hline Lisa et $\mathrm{a}^{21}$ & 147 & 80 & Prospective case series \\
\hline Fernández-Vigo et a ${ }^{80}$ & 50 & 25 & Prospective case series \\
\hline Shimizu et $\mathrm{al}^{63}$ & 32 & 16 & Prospective case series \\
\hline
\end{tabular}

Abbreviation: NR, not reported.

significant (two-sample two-sided $t$-test using pooled mean and standard deviations; $t(2,594)=-1.70 ; P=0.09)$. The $95 \%$ $\mathrm{CI}$ for the difference (V4c minus others) is -3 to $42 \mu \mathrm{m}$.

To address concerns regarding the implications of the central port design on quality of vision, Perez-Vives et a ${ }^{62}$ studied ICL models with and without the central port utilizing an adaptive optics simulator. No statistically significant differences in visual acuity or contrast sensitivity were found between the two models for any ICL powers and pupil sizes evaluated $(P>0.05)$. Regarding the effect of ICL decentration on visual performance, the authors did not find statistically significant differences in visual acuity or contrast sensitivity between centered, $0.3 \mathrm{~mm}$ decentered and $0.6 \mathrm{~mm}$ decentered lenses $(P>0.05)$. Moreover, decentration affected both lens models in the same manner. The authors concluded that both models of ICL provide good and comparable visual performance for all powers and pupil sizes evaluated, regardless of centration.

\section{Effectiveness}

Measures of effectiveness include postoperative UCVA, MRSE, refractive predictability, and refractive stability.

Visual acuity outcomes are provided in Table 5. The efficacy index (postoperative UCVA divided by preoperative BCVA) is 1.00 or greater in all cases in which it was reported. A high percentage of eyes achieved and maintained 20/20 or better UCVA. In the study with the longest available follow-up, Shimizu et $\mathrm{a}^{63}$ reported that:

The postoperative UDVAs of the Hole ICL group were $20 / 20$ or better 1,3 , and 6 months and 1, 3, and 5 years postoperatively, in $97 \%, 100 \%, 100 \%, 100 \%, 100 \%$, and $85 \%$ of eyes, respectively $[\ldots]^{63}$
Table 5 Postoperative UCVA for V4c reported at final visit

\begin{tabular}{|c|c|}
\hline Study & IogMAR UCVA \\
\hline Shimizu et $\mathrm{al}^{79}$ & $-0.20 \pm 0.12$ \\
\hline Alfonso et $\mathrm{al}^{65}$ & $0.009 \pm 0.062$ \\
\hline Kamiya et al ${ }^{69}$ & $-0.20 \pm 0.1 \mathrm{I}(95 \% \mathrm{Cl}, 0.03-0.42)$ \\
\hline Higueras-Esteban et al ${ }^{67}$ & $-0.07 \pm 0.11$ \\
\hline Huseynova et al ${ }^{64}$ & $-0.13 \pm 0.08$ (Range: -0.30 to 0.10$)$ \\
\hline Lisa et $\mathrm{a}^{21}$ & $0.028 \pm 0.055$ \\
\hline Fernández-Vigo et a $\left.\right|^{80}$ & $0.05 \pm 0.1$ I (Range: 0.0 to 0.4 ) \\
\hline Shimizu et $\mathrm{al}^{63}$ & $-0.17 \pm 0.14$ (Range: -0.30 to 0.15 ) \\
\hline
\end{tabular}

Note: Data are presented as mean \pm standard deviation.

Abbreviations: UCVA, uncorrected visual acuity; $\mathrm{Cl}$, confidence interval.

Postoperative MRSE data are provided in Table 6. Mean absolute MRSE was less than 0.3 D in all studies for which it was reported. Excellent predictability is demonstrated by the high percentage of eyes achieving MRSE within 0.5 and 1.0 D of emmetropia. Postoperative refractive spherical equivalent has also been shown to vary little during the postoperative period.

\section{Safety}

Specific reported safety outcomes related to VICMO implantation include preservation of BCVA, changes in IOP, endothelial cell loss, quality of vision, and cataract. Table 7 provides postoperative BCVA from studies with available data, while Table 8 provides gain or loss of lines of BCVA. The majority of eyes maintained preoperative BCVA, while a significant proportion gained 1 or more lines.

The safety index is the ratio of postoperative to preoperative BCVA. Huseynova et al ${ }^{64}$ noted that, "The safety index at 3 months was 1.07 (for Group I [V4b]) and 1.14 (for Group II [VICMO])". Lisa et al found a safety index of $1.04,{ }^{21}$ and Alfonso et al reported a safety index of $1.01{ }^{65}$ The postoperative increase in BCVA is not unexpected, given the beneficial elimination of spectacle-related minification in moderate to severe myopia.

Table 6 Postoperative MRSE for V4c

\begin{tabular}{|c|c|c|c|}
\hline Study & Postop MRSE D & $\begin{array}{l}\% \text { within } \\
\pm 0.50 \text { D }\end{array}$ & $\begin{array}{l}\% \text { within } \\
\pm \text { I.O D }\end{array}$ \\
\hline Alfonso et $\mathrm{al}^{65}$ & $0.03 \pm 0.19$ & 98.6 & 100 \\
\hline Kamiya et al ${ }^{69}$ & $\begin{array}{l}-0.03 \pm 0.20 \\
(95 \% \mathrm{Cl},-0.42 \text { to } 0.37)\end{array}$ & & \\
\hline Higueras-Esteban et $\mathrm{a}^{67}$ & $-0.3 \pm 0.5$ & & \\
\hline Huseynova et al ${ }^{64}$ & $\begin{array}{l}0.19 \pm 0.40 \\
\text { (Range: }-0.75 \text { to I.13) }\end{array}$ & 75 & 98 \\
\hline Lisa et $\mathrm{a}^{21}$ & & 93.9 & 100 \\
\hline Fernández-Vigo et a $\left.\right|^{80}$ & $\begin{array}{l}0.01 \pm 0.15 \\
\text { (Range: }-0.375 \text { to } 0.75 \text { ) }\end{array}$ & & \\
\hline
\end{tabular}

Note: Data are presented as mean \pm standard deviation.

Abbreviations: MRSE, manifest refractive spherical equivalent; Postop, postoperative; $\mathrm{Cl}$, confidence interval. 
Table 7 Postoperative logMAR BCVA for $\mathrm{V} 4 \mathrm{c}$ reported at final visit

\begin{tabular}{ll}
\hline Study & BCVA \\
\hline Alfonso et a $\left.\right|^{65}$ & $-0.015 \pm 0.032$ \\
Kamiya et al & $-0.26 \pm 0.06(95 \% \mathrm{Cl},-0.38$ to -0.14$)$ \\
Huseynova et al ${ }^{64}$ & $-0.18 \pm 0.04$ (Range: -0.30 to -0.08$)$ \\
Lisa et al $^{21}$ & $0.003 \pm 0.013$ \\
Fernández-Vigo et al ${ }^{80}$ & $0.04 \pm 0.10$ (Range: 0.0 to 0.2$)$ \\
Shimizu et al ${ }^{63}$ & $-0.24 \pm 0.08$ (Range: -0.30 to -0.08$)$ \\
\hline
\end{tabular}

Note: Data are presented as mean \pm standard deviation.

Abbreviations: BCVA, best corrected logMAR visual acuity; $\mathrm{Cl}$, confidence interval.

In the retrospective case series authored by GonzalezLopez et $\mathrm{al}^{166}$ of 100 eyes implanted with VICMO, no eye had an IOP greater than $30 \mathrm{mmHg}$ at any postoperative measurement. In the retrospective cohort study authored by Higueras-Esteban et al, ${ }^{67}$ which included 18 eyes implanted with VICMO, the authors noted "a mild and transient increase in IOP during the first month; however, no chronically elevated IOP levels or pupillary block were observed in either group." Lisa et $\mathrm{al}^{21}$ noted, regarding their study of 147 eyes of 80 patients implanted with VICMO,

In the present study, we found no significant rise in IOP

$(>20 \mathrm{mmHg})$ in any case, with stable IOP values during

the 12-month follow-up [...]. ${ }^{21}$

Table 9 provides data on ECD following implantation of VICMO. Authors generally employed minimum threshold ECD and ACD criteria for implantation similar to those found in the ICL labeling. The prospective study reported by Lisa et $\mathrm{al}^{21}$ demonstrated a $1.7 \%$ decrease in ECD from baseline at 1 year. Shimizu et $\mathrm{al}^{63}$ have provided the longest term follow-up of endothelial cell loss with VICMO, reporting that "The mean percentage of endothelial cell loss 5 years postoperatively was $0.5 \% \pm 5.4 \%$."

Shimizu et a ${ }^{68}$ studied higher order aberrations, contrast sensitivity, and symptoms in a prospective, intraindividual investigation of 29 subjects. For 4 and $6 \mathrm{~mm}$ pupils, the changes after VICMO ICL implantation in coma-like aberrations, spherical-like aberrations, and total higher order aberrations were similar to those after ICL implantation ( $P>0.05$, Wilcoxon signed rank test). The postoperative area under the $\log$ contrast sensitivity function was significantly increased after VICMO implantation $(P<0.05)$ and was equivalent to that after ICL implantation under photopic, mesopic, and mesopic with glare conditions. Subjective symptoms such as glare or halo were also essentially equivalent after VICMO or ICL implantation.

These findings were echoed by Kamiya et al, ${ }^{69}$ who concluded from an interindividual comparative study of modulation transfer function cutoff frequency, Strehl ratio, objective scattering index, and Optical Quality Analysis System values, using an optical quality analysis system, that VICMO:

Implantation appears to be essentially equivalent in the optical quality variables to conventional ICL implantation, suggesting that the presence of the central artificial hole does not significantly affect the optical quality and the intraocular scattering after surgery.

Huseynova et al ${ }^{64}$ also found no significant difference in wavefront aberrations between VICMO and ICL subjects.

Eight of the twelve published studies on VICMO listed in Table 4 specifically report the incidence of adverse events. These eight studies include data on 1,291 eyes followed for up to 5 years $^{63}$ and describe a zero incidence of asymptomatic ASC opacities, visually significant cataract, pupillary block, and pigment dispersion glaucoma.

Brar et $\mathrm{a}^{44}$ have provided valuable additional data on the incidence of cataract over 5 years following ICL implantation in a total of 957 eyes, including 342 eyes implanted with the VICMO and 615 eyes implanted with the ICL. ICL explantation due to ICL-related cataract (ie, ASC cataract) was very low in this series, four out of 957 eyes $(0.5 \%)$. All ICLs that were explanted due to cataract were the older ICL model. The authors note "No V4c ICL was explanted due to cataract in this series".

Results from preclinical and clinical studies of VICMO summarized in this review demonstrate that the addition of the central port maintains effectiveness equivalent to the FDA approved Visian ICL, and provides equivalent quality of vision and safety without the requirement for preoperative

Table 8 Lines gained or lost, n (\%)

\begin{tabular}{|c|c|c|c|c|c|c|}
\hline Study & Lost 2 & Lost I & No change & Gained I & Gained 2 & $\begin{array}{l}\text { Gained } 3 \\
\text { or more }\end{array}$ \\
\hline Alfonso et $\mathrm{a}^{65}$ & 0 & 0 & 113 (8I.9) & $21(15.2)$ & $4(2.9)$ & 0 \\
\hline Huseynova et $\mathrm{al}^{64}$ & 0 & 0 & $24(55)$ & $16(36)$ & $3(7)$ & I (I) \\
\hline Lisa et $\mathrm{a}^{21}$ & 0 & 0 & I I 6 (78.9) & $21(14.3)$ & $5(3.4)$ & $5(3.4)$ \\
\hline Shimizu et $\mathrm{al}^{63}$ & 0 & $4(15)$ & $9(35)$ & II (42) & $2(8)$ & 0 \\
\hline
\end{tabular}


Table 9 Endothelial cell loss reported for V4c

\begin{tabular}{lll}
\hline Study & Time point & Percent change \\
\hline Huseynova et al $^{64}$ & 3 months & $+0.0 \mathrm{I}$ \\
Fernández-Vigo et al $^{80}$ & 3 months & -6.8 \\
Shimizu et al ${ }^{79}$ & 6 months & -2.8 \\
Alfonso et al $^{65}$ & 6 months & -8.5 \\
Lisa et al $^{21}$ & I year & -1.7 \\
Shimizu et al ${ }^{63}$ & 5 years & $-0.5 \pm 5.4$ \\
\hline
\end{tabular}

iridotomies. Additional follow-up is necessary to determine whether the more physiologic central port design will continue to improve the long-term safety profile of the ICL.

\section{Conclusion}

In the decade since FDA approval, researchers have produced a large body of scientific evidence demonstrating the safety and effectiveness of the ICL and, more recently, VICMO. Although controversy has surrounded the methodology of sizing, metaanalysis of the peer-reviewed, scientific literature demonstrates that all currently reported techniques achieve similarly satisfactory results in terms of achieved vault. The reported rates of complications related to vault have generally remained low, except in those case series where additional risk factors such as higher levels of myopia and older age have impacted the incidence of cataract. Given the significant improvements in vision and quality of life made possible by the ICL, and the high degree of patient satisfaction associated with its use, the benefits of ICL implantation continue to outweigh the risks.

\section{Disclosure}

The author is a Consultant to STAAR Surgical, Inc., Alcon Laboratories (Novartis AG), Bausch \& Lomb (Valeant International Pharmaceuticals, Inc.). The author reports no other conflicts of interest in this work.

\section{References}

1. Food and Drug Administration. Summary of safety and effectiveness data, STAAR Visian ICL. Date of Notice of Approval: December 22, 2005. Available from: http://www.accessdata.fda.gov/cdrh_docs/pdf3/ P030016b.pdf. Accessed March 31, 2016.

2. STAAR Surgical Reports Fourth Quarter and Full Year 2015 Results. Available from: http://finance.yahoo.com/news/staar-surgical-reportsfourth-quarter-210100370.html. Accessed April 18, 2016.

3. Price MO, Price FW Jr. Evaluation of the toric implantable Collamer lens for simultaneous treatment of myopia and astigmatism. Expert Rev Med Devices. 2015;12(1):25-39.

4. Sanders DR, Doney K, Poco M; ICL in Treatment of Myopia Study Group. United States Food and Drug Administration clinical trial of the implantable Collamer lens (ICL) for moderate to high myopia: three-year follow-up. Ophthalmology. 2004;111(9):1683-1692.

5. Lisa C, Alfonso JF, Alfonso-Bartolozzi B, Fernández-Vega L, PérezVives C, Montés-Micó R. Collagen copolymer posterior chamber phakic intraocular lens supported by the ciliary sulcus to treat myopia: one-year follow-up. J Cataract Refract Surg. 2015;41(1):98-104.
6. Schallhorn S, Tanzer D, Sanders DR, Sanders ML. Randomized prospective study of visian implantable Collamer lens and conventional photorefractive keratectomy for moderate to high myopic astigmatism. J Refract Surg. 2007;23:853-857.

7. Ieong A, Hau SC, Rubin GS, Allan BD. Quality of life in high myopia before and after implantable Collamer lens implantation. Ophthalmology. 2010;117(12):2295-2300.

8. Sanders DR. Anterior subcapsular opacities and cataracts 5 years after surgery in the visian implantable Collamer lens FDA trial. $J$ Refract Surg. 2008;24(6):566-570.

9. Dougherty PJ, Rivera RP, Schneider D, Lane SS, Brown D, Vukich J. Improving accuracy of phakic intraocular lens sizing using high-frequency ultrasound biomicroscopy. J Cataract Refract Surg. 2011;37(1): 13-18.

10. McLeod SD. Long-term clinical outcomes and cataract formation rates after posterior phakic lens implantation for myopia. JAMA Ophthalmol. Epub March 3, 2016.

11. Igarashi A, Shimizu K, Kamiya K. Eight-year follow-up of posterior chamber phakic intraocular lens implantation for moderate to high myopia. Am J Ophthalmol. 2014;157(3):532-539.e1.

12. Lee JS, Kim YH, Park SK, et al. Long-term clinical results of posterior chamber phakic intraocular lens implantation to correct myopia. Clin Experiment Ophthalmol. Epub December 12, 2015.

13. Alfonso JF, Baamonde B, Fernández-Vega L, Fernandes P, GonzálezMéijome JM, Montés-Micó R. Posterior chamber collagen copolymer phakic intraocular lenses to correct myopia: five-year follow-up. $J$ Cataract Refract Surg. 2011;37(5):873-880.

14. Rose K, Harper R, Tromans C, et al. Quality of life in myopia. $\mathrm{Br}$ J Ophthalmol. 2000;84(9):1031-1034.

15. Kobashi H, Kamiya K, Igarashi A, Matsumura K, Komatsu M, Shimizu K. Long-term quality of life after posterior chamber phakic intraocular lens implantation and after wavefront-guided laser in situ keratomileusis for myopia. J Cataract Refract Surg. 2014;40(12):2019-2024.

16. Gonvers M, Bornet C, Othenin-Girard P. Implantable contact lens for moderate to high myopia: relationship of vaulting to cataract formation. J Cataract Refract Surg. 2003;29(5):918-924.

17. Schmidinger G, Lackner B, Pieh S, Skorpik C. Long-term changes in posterior chamber phakic intraocular Collamer lens vaulting in myopic patients. Ophthalmology. 2010;117(8):1506-1511.

18. Zeng Q, Xie X, Chen Q. Prevention and management of collagen copolymer phakic intraocular lens exchange: causes and surgical techniques. $J$ Cataract Refract Surg. 2015;41:576-584.

19. Rayner SA, Bhikoo R, Gray T. Spherical implantable Collamer lenses for myopia and hyperopia: 126 eyes with 1-year follow up. Clin Experiment Ophthalmol. 2010;38(1):21-26.

20. Bhikoo R, Rayner S, Gray T. Toric implantable Collamer lens for patients with moderate to severe myopic astigmatism: 12-month follow-up. Clin Experiment Ophthalmol. 2010;38(5):467-474.

21. Lisa C, Naveiras M, Alfonso-Bartolozzi B, Belda-Salmerón L, Montés-Micó R, Alfonso JF. Posterior chamber collagen copolymer phakic intraocular lens with a central hole to correct myopia: one-year follow-up. J Cataract Refract Surg. 2015;41(6):1153-1159.

22. Maeng HS, Chung TY, Lee DH, Chung ES. Risk factor evaluation for cataract development in patients with low vaulting after phakic intraocular lens implantation. $J$ Cataract Refract Surg. 2011;37(5):881-885.

23. Salouti R, Nowroozzadeh MH, Zamani M, Ghoreyshi M, Khodaman AR. Comparison of Horizontal corneal diameter measurements using the Orbscan IIz and Pentacam HR systems. Cornea. 2013;32(11): $1460-1464$.

24. Sheng XL, Rong WN, Jia Q, et al. Outcomes and possible risk factors associated with axis alignment and rotational stability after implantation of the Toric implantable Collamer lens for high myopic astigmatism. Int J Ophthalmol. 2012;5(4):459-465.

25. Malyugin BE, Shpak AA, Pokrovskiy DF. Posterior chamber phakic intraocular lens sizing based on iris pigment layer measurements by anterior segment optical coherence tomography. $J$ Cataract Refract Surg. 2015;41(8):1616-1622. 
26. Kojima T, Yokoyama S, Ito M, et al. Optimization of an implantable Collamer lens sizing method using high-frequency ultrasound biomicroscopy. Am J Ophthalmol. 2012;153(4):632-637.e1.

27. Pop M, Payette Y, Mansour M. Predicting sulcus size using ocular measurements. J Cataract Refract Surg. 2001;27(7):1033-1038.

28. Oh J, Shin HH, Kim JH, Kim HM, Song JS. Direct measurement of the ciliary sulcus diameter by 35-megahertz ultrasound biomicroscopy. Ophthalmology. 2007;114(9):1685-1688.

29. Rondeau MJ, Barcsay G, Silverman RH, et al. Very high frequency ultrasound biometry of the anterior and posterior chamber diameter. J Refract Surg. 2004;20(5):454-464.

30. Reinstein DZ, Archer TJ, Silverman RH, Rondeau MJ, Coleman DJ. Correlation of anterior chamber angle and ciliary sulcus diameters with white-to-white corneal diameter in high myopes using artemis VHF digital ultrasound. J Refract Surg. 2009;25(2):185-194.

31. Guber I, Bergin C, Perritaz S, Majo F. Correcting interdevice bias of horizontal white-to-white and sulcus-to-sulcus measures used for implantable Collamer lens sizing. Am J Ophthalmol. 2016;161: 116-125 e1.

32. Yokoyama S, Kojima T, Horai R, Ito M, Nakamura T, Ichikawa K. Repeatability of the ciliary sulcus-to-sulcus diameter measurement using wide-scanning-field ultrasound biomicroscopy. J Cataract Refract Surg. 2011;37(7):1251-1256.

33. Werner L, Izak AM, Pandey SK, Apple DJ, Trivedi RH, Schmidbauer JM. Correlation between different measurements within the eye relative to phakic intraocular lens implantation. J Cataract Refract Surg. 2004;30:1982-1988.

34. Piñero DP, Puche AB, Alió JL. Ciliary sulcus diameter and two anterior chamber parameters measured by optical coherence tomography and VHF ultrasound. J Refract Surg. 2009;25(11):1017-1025.

35. Alfonso JF, Fernández-Vega L, Lisa C, Fernandes P, GonzálezMeijome J, Montés-Micó R. Long-term evaluation of the central vault after phakic Collamer ${ }^{\mathbb{R}}$ lens (ICL) implantation using OCT. Graefes Arch Clin Exp Ophthalmol. 2012;250(12):1807-1812.

36. Du GP, Huang YF, Wang LQ, et al. Changes in objective vault and effect on vision outcomes after implantable Collamer lens implantation: 1-year follow-up. Eur J Ophthalmol. 2012;22(2):153-160.

37. Reinstein DZ, Lovisolo CF, Archer TJ, Gobbe M. Comparison of postoperative vault height predictability using white-to-white or sulcus diameter-based sizing for the visian implantable Collamer lens. J Refract Surg. 2013;29(1):30-35.

38. Alfonso JF, Lisa C, Palacios A, Fernandes P, González-Méijome JM, Montés-Micó R. Objective vs subjective vault measurement after myopic implantable Collamer lens implantation. Am J Ophthalmol. 2009; 147(6):978-983.e1.

39. Lee DH, Choi SH, Chung ES, Chung TY. Correlation between preoperative biometry and posterior chamber phakic Visian Implantable Collamer Lens vaulting. Ophthalmology. 2012;119(2):272-277.

40. Choi KH, Chung SE, Chung TY, Chung ES. Ultrasound biomicroscopy for determining Visian implantable contact lens length in phakic IOL implantation. J Refract Surg. 2007;23:362-367.

41. Ghoreishi M, Mohammadinia M. Correlation between Preoperative Sizing of Implantable Collamer Lens (ICL) by white-to-white and sulcus-to-sulcus techniques, and postoperative vault size measured by scheimpflug imaging. J Clin Experiment Ophthalmol. 2014;5:351.

42. Sanders DR, Vukich JA, Doney K, Gaston M; Implantable Contact Lens in Treatment of Myopia Study Group. US Food and Drug Administration clinical trial of the implantable contact lens for moderate to high myopia. Ophthalmology. 2003;110(2):255-266.

43. Alfonso JF, Lisa C, Fernández-Vega L, Almanzar D, Pérez-Vives C, Montés-Micó R. Prevalence of cataract after collagen copolymer phakic intraocular lens implantation for myopia, hyperopia, and astigmatism. J Cataract Refract Surg. 2015;41(4):800-805.

44. Brar S, Ganeresh S, Pandey R. Incidence \& factors responsible for implantable Collamer lens (ICL) explantation \& outcomes of further management-5 year retrospective study. EC Ophthalmology. 2015;3(1): 231-239.
45. Leske MC, Wu SY, Nemesure B, Li X, Hennis A, Connell AM. Incidence and progression of lens opacities in the Barbados Eye Studies. Ophthalmology. 2000;107(7):1267-1273.

46. Wong TY, Klein BE, Klein R, Tomany SC, Lee KE. Refractive errors and incident cataracts: the Beaver Dam Eye Study. Invest Ophthalmol Vis Sci. 2001;42:1449-1454.

47. Leske MC, Chylack LT Jr, He Q, et al. Incidence and progression of cortical and posterior subcapsular opacities: the longitudinal study of cataract. Ophthalmology. 1997;104:1987-1993.

48. Sperduto RD, Seigel D. Senile lens and senile macular changes in a population-based sample. Am J Ophthalmol. 1980;90:86-91.

49. Klein BE, Klein R, Linton KL. Prevalence of age-related lens opacities in a population. The Beaver Dam Eye Study. Ophthalmology. 1992;99: 546-552.

50. Iijima K, Kamiya K, Shimizu K, Igarashi A, Komatsu M. Demographics of patients having cataract surgery after laser in situ keratomileusis. J Cataract Refract Surg. 2015;41(2):334-338.

51. Kubo E, Kumamoto Y, Tsuzuki S, Akagi Y. Axial length, myopia, and the severity of lens opacity at the time of cataract surgery. Arch Ophthalmol. 2006;124(11):1586-1590.

52. Chang MA, Congdon NG, Bykhovskaya I, Munoz B, West SK. The association between myopia and various subtypes of lens opacity: SEE (Salisbury Eye Evaluation) project. Ophthalmology. 2005;112(8): 1395-1401.

53. Wong TY, Foster PJ, Johnson GJ, Seah SK. Refractive errors, axial ocular dimensions, and age-related cataracts: the Tanjong Pagar survey. Invest Ophthalmol Vis Sci. 2003;44(4):1479-1485.

54. Kanthan GL, Mitchell P, Rochtchina E, Cumming RG, Wang JJ. Myopia and the long-term incidence of cataract and cataract surgery: the Blue Mountains Eye Study. Clin Experiment Ophthalmol. 2014;42(4): 347-353.

55. Micelli-Ferrari T, Vendemiale G, Grattagliano I, et al. Role of lipid peroxidation in the pathogenesis of myopic and senile cataract. $\mathrm{Br} J$ Ophthalmol. 1996;80(9):840-843.

56. Guber I, Mouvet V, Bergin C, Perritaz S, Othenin-Girard P, Majo F. Clinical outcomes and cataract formation rates in eyes 10 years after posterior phakic lens implantation for myopia. JAMA Ophthalmol. Epub March 3, 2016.

57. Mitchell P, Hourihan F, Sandbach J, Wang JJ. The relationship between glaucoma and myopia: the Blue Mountains Eye Study. Ophthalmology. 1999;106(10):2010-2015

58. Moya T, Javaloy J, Montés-Micó R, Beltrán J, Muñoz G, Montalbán R. Implantable Collamer lens for myopia: assessment 12 years after implantation. J Refract Surg. 2015;31(8):548-556.

59. Kamiya K, Shimizu K, Igarashi A, Aizawa D, Ikeda T. Clinical outcomes and patient satisfaction after Visian Implantable Collamer Lens removal and phacoemulsification with intraocular lens implantation in eyes with induced cataract. Eye (Lond). 2010;24(2):304-309.

60. Fujisawa K, Shimizu K, Uga S, et al. Changes in the crystalline lens resulting from insertion of a phakic IOL (ICL) into the porcine eye. Graefes Arch Clin Exp Opthalmol. 2007;245(1):114-122.

61. Shiratani T, Shimizu K, Fujisawa K, Uga S, Nagano K, Murakami Y. Crystalline lens changes in porcine eyes with implanted phakic IOL (ICL) with a central hole. Graefes Arch Clin Exp Ophthalmol. 2008; 246(5):719-728.

62. Pérez-Vives C, Ferrer-Blasco T, Madrid-Costa D, García-Lázaro S, Montés-Micó R. Visual quality comparison of conventional and HoleVisian implantable Collamer lens at different degrees of decentering. Br J Ophthalmol. 2014;98(1):59-64.

63. Shimizu K, Kamiya K, Igarashi A, Kobashi H. Long-term comparison of posterior chamber phakic intraocular lens with and without a central hole (Hole ICL and Conventional ICL) implantation for moderate to high myopia and myopic astigmatism: consort-compliant article. Medicine (Baltimore). 2016;95(14):e3270.

64. Huseynova T, Ozaki S, Ishizuka T, Mita M, Tomita M. Comparative study of 2 types of implantable Collamer lenses, 1 with and 1 without a central artificial hole. Am J Ophthalmol. 2014;157(6):1136-1143. 
65. Alfonso JF, Lisa C, Fernández-Vega Cueto L, Belda-Salmerón L, Madrid-Costa D, Montés-Micó R. Clinical outcomes after implantation of a posterior chamber collagen copolymer phakic intraocular lens with a central hole for myopic correction. J Cataract Refract Surg. 2013;39(6): 915-921.

66. Gonzalez-Lopez F, Bilbao-Calabuig R, Mompean B, et al. Intraocular pressure during the early postoperative period after 100 consecutive implantations of posterior chamber phakic intraocular lenses with a central hole. J Cataract Refract Surg. 2013;39(12):1859-1863.

67. Higueras-Esteban A, Ortiz-Gomariz A, Gutiérrez-Ortega R, et al. Intraocular pressure after implantation of the Visian Implantable Collamer Lens With CentraFLOW without iridotomy. Am J Ophthalmol. 2013;156(4):800-805.

68. Shimizu K, Kamiya K, Igarashi A, Shiratani T. Intraindividual comparison of visual performance after posterior chamber phakic intraocular lens with and without a central hole implantation for moderate to high myopia. Am J Ophthalmol. 2012;154(3):486-494.

69. Kamiya K, Shimizu K, Saito A, Igarashi A, Kobashi H. Comparison of optical quality and intraocular scattering after posterior chamber phakic intraocular lens with and without a central hole (Hole ICL and Conventional ICL) implantation using the double-pass instrument. PLoS One. 2013;8(6):e66846.

70. Seo JH, Kim MK, Wee WR, Lee JH. Effects of white-to-white diameter and anterior chamber depth on implantable Collamer lens vault and visual outcome. J Refract Surg. 2009;25(8):730-738.

71. Kojima T, Maeda M, Yoshida Y, et al. Posterior chamber phakic implantable Collamer lens: changes in vault during 1 year. $J$ Refract Surg. 2010;26(5):327-332.

72. Alfonso JF, Fernández-Vega L, Lisa C, Fernandes P, Jorge J, Montés Micó R. Central vault after phakic intraocular lens implantation: correlation with anterior chamber depth, white-to-white distance, spherical equivalent, and patient age. J Cataract Refract Surg. 2012; 38(1):46-53.
73. Cao X, Tong J, Wang Y, et al. Long-term ultrasound biomicroscopy observation of position changes of a copolymer posterior chamber phakic intraocular lens. J Cataract Refract Surg. 2014;40(9):1454-1461.

74. Lee H, Kang SY, Seo KY, et al. Dynamic vaulting changes in V4c versus V4 posterior chamber phakic lenses under differing lighting conditions. Am J Ophthalmol. 2014;158(6):1199-1204.e1.

75. Alfonso JF, Lisa C, Alfonso-Bartolozzi B, Pérez-Vives C, MontésMicó R. Collagen copolymer toric phakic intraocular lens for myopic astigmatism: one-year follow-up. J Cataract Refract Surg. 2014;40(7): $1155-1162$

76. Gomez-Bastar A, Jaimes M, Graue-Hernández EO, Ramirez-Luquin T, Ramirez-Miranda A, Navas A. Long-term refractive outcomes of posterior chamber phakic (spheric and toric implantable Collamer lens) intraocular lens implantation. Int Ophthalmol. 2014;34(3):583-590.

77. Kamiya K, Shimizu K, Ando W, Igarashi A, Iijima K, Koh A Comparison of vault after implantation of posterior chamber phakic intraocular lens with and without a central hole. J Cataract Refract Surg. 2015;41(1):67-72.

78. Kamiya K, Shimizu K, Igarashi A, Hikita F, Komatsu M. Four-year follow-up of posterior chamber phakic intraocular lens implantation for moderate to high myopia. Arch Ophthalmol. 2009;127(7):845-850.

79. Shimizu K, Kamiya K, Igarashi A, Shiratani T. Early clinical outcomes of implantation of posterior chamber phakic intraocular lens with a central hole (Hole ICL) for moderate to high myopia. Br J Ophthalmol. 2012; 96(3):409-412.

80. Fernández-Vigo JI, Macarro-Merino A, Fernández-Vigo C, et al. Effects of implantable Collamer lens V4c placement on iridocorneal angle measurements by fourier-domain optical coherence tomography. $\mathrm{Am}$ J Ophthalmol. 2016;162:43-52.e1.
Clinical Ophthalmology

\section{Publish your work in this journal}

Clinical Ophthalmology is an international, peer-reviewed journa covering all subspecialties within ophthalmology. Key topics include: Optometry; Visual science; Pharmacology and drug therapy in eye diseases; Basic Sciences; Primary and Secondary eye care; Patien Safety and Quality of Care Improvements. This journal is indexed on

\section{Dovepress}

PubMed Central and CAS, and is the official journal of The Society of Clinical Ophthalmology (SCO). The manuscript management system is completely online and includes a very quick and fair peer-review system, which is all easy to use. Visit http://www.dovepress.com/ testimonials.php to read real quotes from published authors. 